\title{
Buffering of cytosolic calcium plays a neuroprotective role by preserving the autophagy-lysosome pathway during $\mathrm{MPP}^{+}$-induced neuronal death
}

Shinae Jung ${ }^{1}$, Yuhyun Chung ${ }^{1}$, Yunsoo Lee ${ }^{1}$, Yangsin Lee ${ }^{2}$, Jin Won Cho ${ }^{1,2}$, Eun-Joo Shin ${ }^{3}$, Hyoung-Chun Kim ${ }^{3}$ and Young J. $\mathrm{Oh}^{1}$

\begin{abstract}
Parkinson's disease (PD) is a chronic neurodegenerative disease with no cure. Calbindin, a $\mathrm{Ca}^{2+}$-buffering protein, has been suggested to have a neuroprotective effect in the brain tissues of PD patients and in experimental models of PD. However, the underlying mechanisms remain elusive. Here, we report that in 1-methyl-4-phenylpyridinium $\left(\mathrm{MPP}^{+}\right)$induced culture models of PD, the buffering of cytosolic $\mathrm{Ca}^{2+}$ by calbindin-D28 overexpression or treatment with a chemical $\mathrm{Ca}^{2+}$ chelator reversed impaired autophagic flux, protecting cells against MPP ${ }^{+}$-mediated neurotoxicity. When cytosolic $\mathrm{Ca}^{2+}$ overload caused by $\mathrm{MPP}^{+}$was ameliorated, the $\mathrm{MPP}^{+}$-induced accumulation of autophagosomes decreased and the autophagic flux significantly increased. In addition, the accumulation of damaged mitochondria and p62-positive ubiquitinated protein aggregates, following MPP ${ }^{+}$intoxication, was alleviated by cytosolic $\mathrm{Ca}^{2+}$ buffering. We showed that $\mathrm{MPP}^{+}$treatment suppressed autophagic degradation via raising the lysosomal $\mathrm{pH}$ and therefore reducing cytosolic $\mathrm{Ca}^{2+}$ elevation restored the lysosomal $\mathrm{pH}$ acidity and normal autophagic flux. These results support the notion that functional lysosomes are required for $\mathrm{Ca}^{2+}$-mediated cell protection against $\mathrm{MPP}^{+}$-mediated neurotoxicity. Thus, our data suggest a novel process in which the modulation of $\mathrm{Ca}^{2+}$ confers neuroprotection via the autophagy-lysosome pathway. This may have implications for the pathogenesis and future therapeutic targets of PD.
\end{abstract}

\section{Introduction}

Parkinson's disease (PD) is accompanied with a progressive loss of dopaminergic neurons in the substantia nigra pars compacta $(\mathrm{SNpc})$ and dopamine depletion in the striatum ${ }^{1,2}$. Although the etiology of PD is unclear, accumulating evidence suggests that abnormal protein aggregation, mitochondrial dysfunction, and dysregulated $\mathrm{Ca}^{2+}$ homeostasis may be involved in the

Correspondence: Young J. Oh (yjoh@yonsei.ac.kr)

${ }^{1}$ Department of Systems Biology, Yonsei University College of Life Science and Biotechnology, Seoul 03722, Korea

${ }^{2}$ Glycosylation Network Research Center, Yonsei University, Seoul 03722, Korea Full list of author information is available at the end of the article.

Edited by R. Killick neurodegeneration observed in $\mathrm{PD}^{3-6}$. Recently, advances have been made in defining cell death modes associated with the pathogenesis of $\mathrm{PD}^{7}$. Role of apoptosis has been highlighted in studies using postmortem brains of $\mathrm{PD}$ patients and experimental models of PD that were generated by applying familial cases of gene mutations or treatment with neurotoxins ${ }^{8}$. Accumulating evidence implicates other cell death modes including necrosis, necroptosis, and parthanatos ${ }^{9,10}$. More recently, dysregulated autophagic pathway has been found in postmortem $\mathrm{PD}$ brains and in experimental models of $\mathrm{PD}^{11-13}$.

Because the intracellular catabolic process through which protein aggregates and damaged subcellular organelles can be degraded, autophagy is linked to PD pathogenesis ${ }^{14-16}$.

\section{(c) The Author(s) 2019}

(c) (i) Open Access This article is licensed under a Creative Commons Attribution 4.0 International License, which permits use, sharing, adaptation, distribution and reproduction cc) in any medium or format, as long as you give appropriate credit to the original author(s) and the source, provide a link to the Creative Commons license, and indicate if changes were made. The images or other third party material in this article are included in the article's Creative Commons license, unless indicated otherwise in a credit line to the material. If material is not included in the article's Creative Commons license and your intended use is not permitted by statutory regulation or exceeds the permitted use, you will need to obtain permission directly from the copyright holder. To view a copy of this license, visit http://creativecommons.org/licenses/by/4.0/. 
Autophagy is a lysosomal degradation pathway, which is categorized into macroautophagy, chaperone-mediated autophagy, and microautophagy. Macroautophagy (hereafter referred to as autophagy) involves double-membrane vesicles called autophagosomes that sequester a portion of the cytosol. After autophagosomes are formed and subsequently fused with late endosomes and/or lysosomes, lysosomal hydrolases digest the internal cargo and the inner membrane of autophagosomes. Autophagy is essential for neuronal homeostasis and acts as a cytoprotective mechanism ${ }^{17-19}$. Consequently, defective autophagy leads to neurodegeneration ${ }^{17,18}$ and cumulative evidence has shown alterations in the autophagy-lysosome pathway in neurodegenerative disorders ${ }^{15}$. Notably, a tight link between autophagy and PD is supported by the finding that many PD-related genes are associated with the autophagylysosome pathway. For instance, parkin and PINK1 play major roles in mitophagy ${ }^{20}$. Similarly, $\alpha$-synuclein is a substrate for chaperone-mediated autophagy, and pathogenic mutants in this gene interfere with that process ${ }^{21}$.

Because pathophysiological changes induced by neurotoxins were reminiscent of those seen in PD patients, these neurotoxins have been used for establishing experimental models of PD and investigating the potential pathophysiology associated with dopaminergic neurodegeneration $^{2}$. Previously, we have suggested that these neurotoxins act on distinct cell death pathways ${ }^{22-24}$. For example, ROS play a crucial role in 6-hydroxydopamine (6-OHDA)-induced apoptosis, whereas treatment with 1methyl-4-phenylpyridinium $\left(\mathrm{MPP}^{+}\right)$causes calciumdependent cell death. We have determined using biochemical and ultrastructural criteria that these neurotoxins trigger autophagy ${ }^{25,26}$. More recently, we have indicated that a 6-OHDA triggers an excessive autophagic flux that precedes apoptosis ${ }^{27}$. Considering the findings that dysregulated autophagic flux may be linked to neuronal death, we questioned whether the buffering of cytosolic $\mathrm{Ca}^{2+}$ regulates the autophagy-lysosome pathway. Here, we demonstrated that $\mathrm{MPP}^{+}$-mediated overload of cytosolic $\mathrm{Ca}^{2+}$ was responsible for defective autophagy and resulted in cell death. We further identified that autophagic malfunction caused by $\mathrm{MPP}^{+}$treatment was due to impaired autophagic degradation associated with lysosomal deficits. Accordingly, our data suggest that limiting the increase of cytosolic $\mathrm{Ca}^{2+}$ protects against $\mathrm{MPP}^{+}$-induced neuronal cell death via preserving the autophagy-lysosome pathway.

\section{Results}

Buffering of cytosolic $\mathrm{Ca}^{2+}$ attenuates $\mathrm{MPP}^{+}$-induced dopaminergic neuronal cell death

As previously demonstrated by us ${ }^{28,29}, 1,2$-Bis(2-aminophenoxy)ethane- $\mathrm{N}, \mathrm{N}, \mathrm{N}^{\prime}, \mathrm{N}^{\prime}$-tetraacetic acid tetrakis (acetoxymethyl ester)[BAPTA-AM] alleviated the elevation of Fluo-3-sensitive cytosolic $\mathrm{Ca}^{2+}$ in MN9D cells treated with $\mathrm{MPP}^{+}$(Fig. 1a, b). $\mathrm{MPP}^{+}$-mediated cell death was inhibited by BAPTA-AM co-treatment (Fig. 1c). Transmission electron microscopy provided evidence that BAPTA-AM protects cells from $\mathrm{MPP}^{+}$toxicity. $\mathrm{MPP}^{+}$treatment resulted in the appearance of swollen mitochondria and autophagic vacuoles (Fig. 1d and Fig. S1). In contrast, co-treatment with BAPTA-AM maintained a pool of intact mitochondria. Similarly, fewer $\mathrm{MPP}^{+}$-induced autophagic vacuoles were detected in MN9D cells co-treated with BAPTA-AM (Fig. 1d). To verify the neuroprotective role of buffering of cytosolic $\mathrm{Ca}^{2+}, \mathrm{MN9D}$ cells were transfected with a vector containing calbindin-D28K (MN9D/CB) or empty control vector (MN9D/Neo; Fig. S2a). $\mathrm{MPP}^{+}$-induced elevation of cytosolic $\mathrm{Ca}^{2+}$ levels observed in MN9D/Neo cells was markedly limited in MN9D/CB \#1 cells (Fig. S2b). In agreement with previous reports ${ }^{30-32}, \mathrm{MPP}^{+}$-induced cell death was suppressed in all three MN9D/CB cell lines (Fig. S2c), demonstrating that the buffering of $\mathrm{MPP}^{+}$induced cytosolic $\mathrm{Ca}^{2+}$ surges inhibited dopaminergic neuronal death.

\section{$\mathrm{MPP}^{+}$-induced autophagosome accumulation is mediated by elevated cytosolic calcium}

Previous reports have demonstrated the existence of autophagosomes in postmortem PD brain and in experimental PD models ${ }^{25,33-35}$. Consistent with these findings, we observed double-membrane autophagosomes and autolysosomes in $\mathrm{MPP}^{+}$-treated cells, whereas these autophagic vacuoles were not easily detected in control cells or $\mathrm{MPP}^{+}$- and BAPTA-AM-co-treated cells (Fig. 1d and Fig. S1). To verify the correlation between cytosolic $\mathrm{Ca}^{2+}$ levels and autophagy during $\mathrm{MPP}^{+}$-induced neurodegeneration, titration experiments were carried out with increasing concentrations of BAPTA-AM, but a fixed dose of $\mathrm{MPP}^{+}$. The levels of LC3-II were increased by $\mathrm{MPP}^{+}$treatment. However, the $\mathrm{MPP}^{+}$-induced increase in LC3-II levels were blocked by BAPTA-AM (Fig. 2a). Immunofluorescence studies revealed that the $\mathrm{MPP}^{+}$. induced increase in the number and average area of LC3 puncta was decreased in MN9D cells co-treated with $\mathrm{MPP}^{+}$and BAPTA-AM (Fig. 2b-d). Immunoblotting and immunofluorescence analyses showed similar results for all three independent MN9D cell lines overexpressing calbindin-D28K (Fig. S3a-d). Taken together, data suggest that suppressing the $\mathrm{MPP}^{+}$-induced rise in cytosolic $\mathrm{Ca}^{2+}$ levels inhibited autophagosomal accumulation in MN9D cells.

\section{Buffering of $\mathrm{MPP}^{+}$-induced surge of cytosolic $\mathrm{Ca}^{2+}$ can normalize the autophagic flux}

To investigate the mechanism underlying autophagosomal accumulation following $\mathrm{MPP}^{+}$treatment, we 

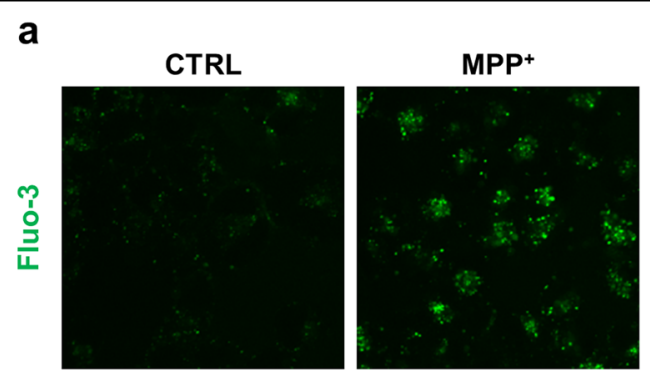

MPP $^{+}$, BAPTA

b

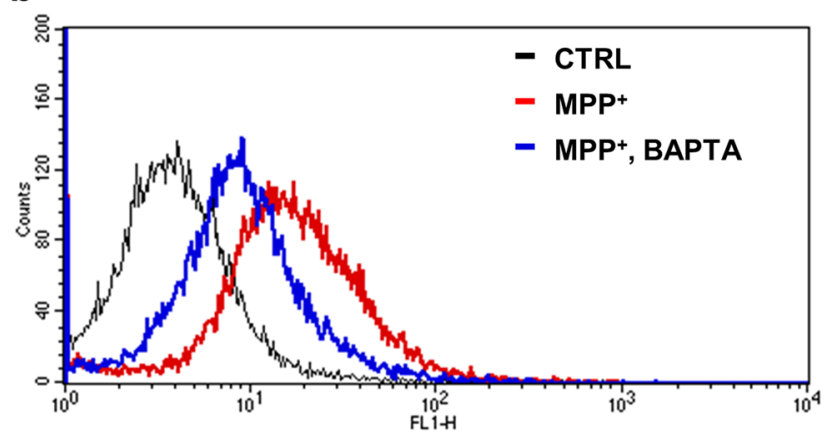

C

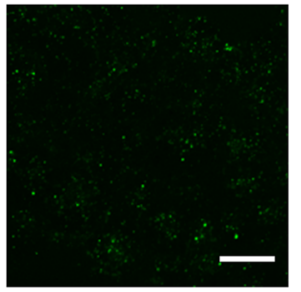

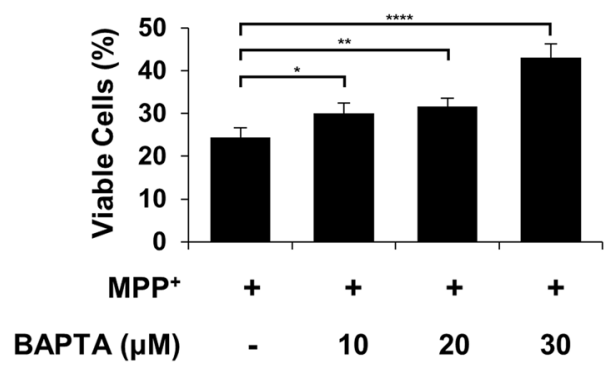

d
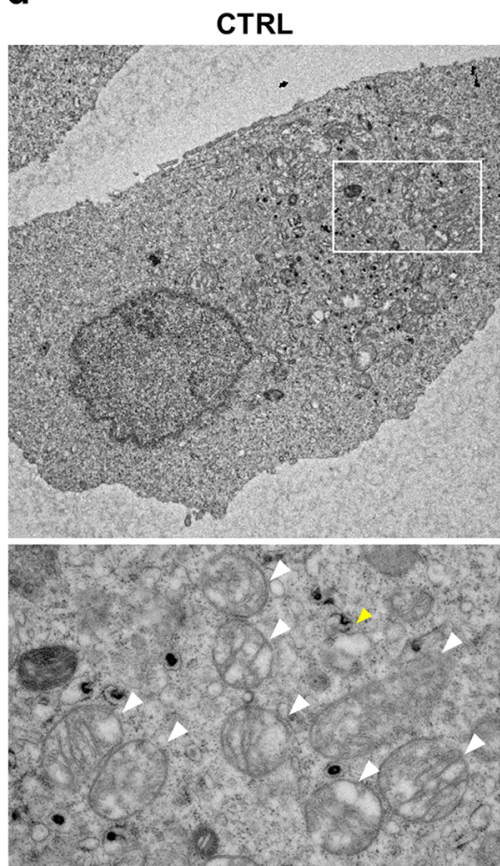

MPP $^{+}$
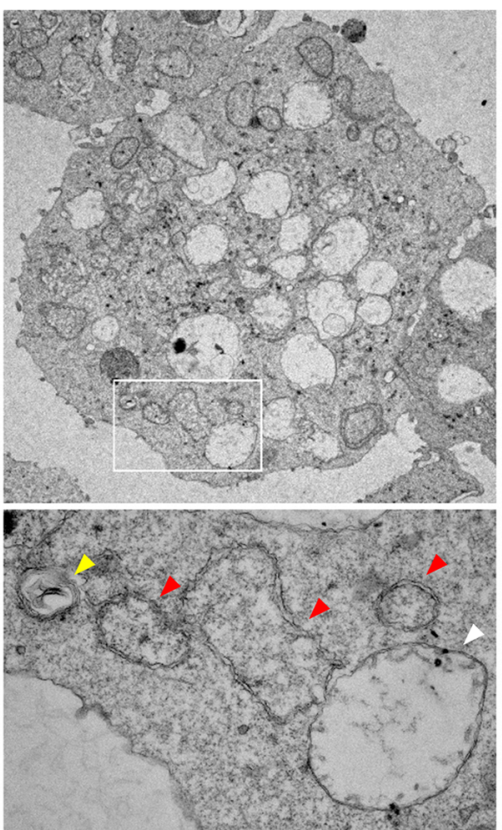

MPP + , BAPTA

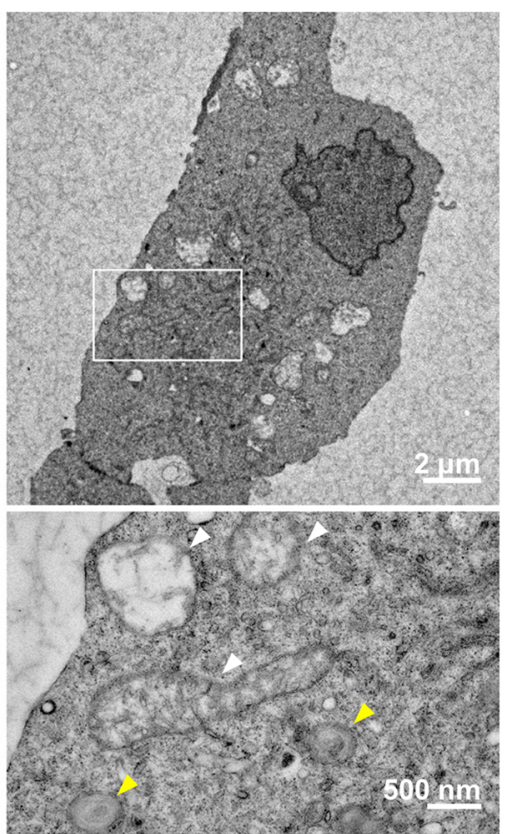

Fig. 1 Buffering of cytosolic calcium attenuates MPP $^{+}$-mediated toxicity in MN9D cells. a-d MN9D cells were treated with vehicle (control, CTRL) or $50 \mu \mathrm{M} \mathrm{MPP}^{+}$in the presence or absence of $30 \mu \mathrm{M}$ BAPTA-AM for $30 \mathrm{~h}$. a MN9D cells were stained with $3 \mu \mathrm{M}$ Fluo-3. A representative image of cells was taken using confocal microscopy after fixation. The scale bar represents $20 \mu \mathrm{m}$. b Cytosolic $\mathrm{Ca}^{2+}$ levels were assessed using flow cytometry. c MTT reduction assays were performed to assess cell viability that is expressed as a percentage of untreated control cells (100\%). Bars represent the mean \pm SEM of three independent experiments in triplicate. ${ }^{*} p<0.05 ;{ }^{* *} p<0.01 ;{ }^{* * * *} p<0.0001$. $\mathbf{d}$ Electron micrographs of MN9D cells were taken after drug treatment. Lower panels are magnified images from the boxed areas. Mitochondria (white arrowheads), lysosomes (yellow arrowheads) and autophagosomes (red arrowheads) are indicated 


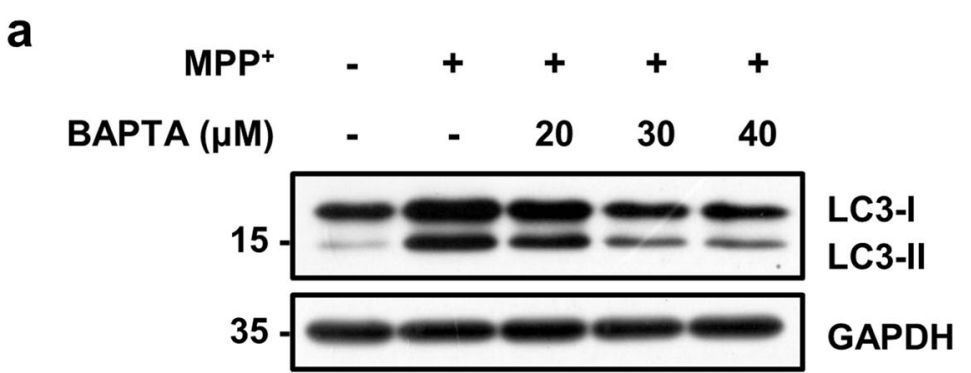

b
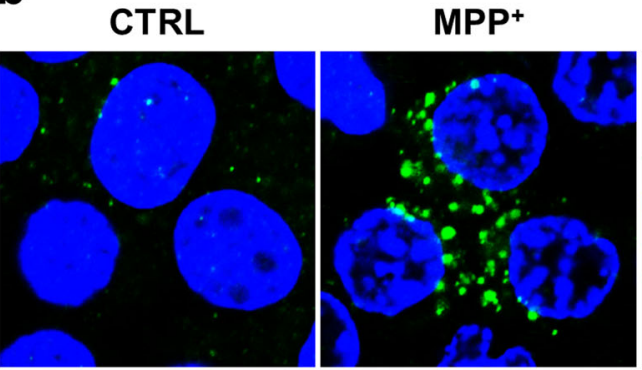

MPP+, BAPTA

C

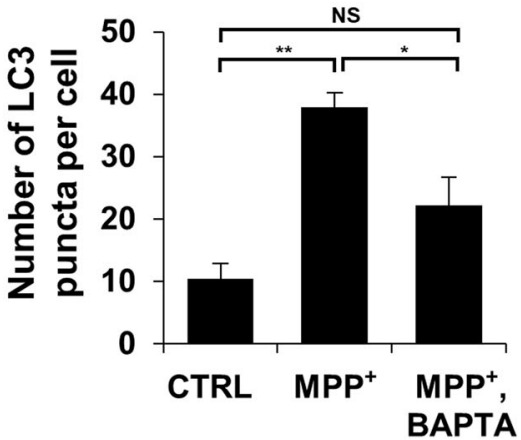

d

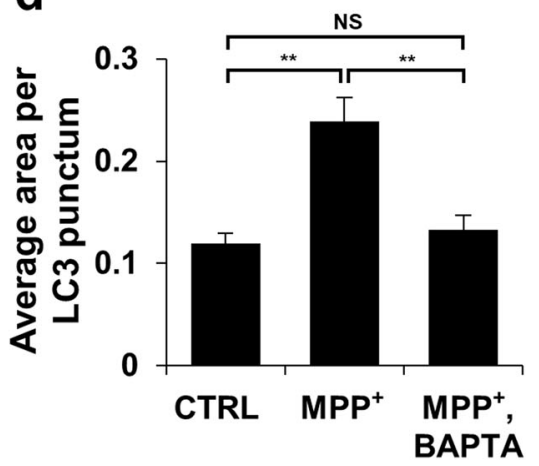

Fig. 2 Reducing cytosolic calcium elevation suppresses the appearance of LC-3-positive autophagosomes caused by MPP ${ }^{+}$treatment. MN9D cells were treated with $50 \mu \mathrm{M} \mathrm{MPP}^{+}$in the presence or absence of the indicated concentrations of BAPTA-AM for $30 \mathrm{~h}$. a Cell lysates were subjected to immunoblot analyses using the anti-LC3 antibody. Anti-GAPDH antibody was used as a loading control. b-d Immunocytochemical analyses were performed using an anti-LC3 antibody (green) and nuclei counterstaining with Hoechst 33258 (blue). b Cells were then examined using a confocal microscope. Merged images are provided. The scale bar represents $10 \mu \mathrm{m}$. The number of LC3 puncta per cell (c) and average puncta area of $L C 3$ (d) were quantified using ImageJ after examining 90 cells per condition. The bar represents the mean \pm SEM of three independent experiments. ${ }^{*} p<0.05 ;{ }^{* *} p<0.01$; NS, not significant

performed an autophagic flux assay using chloroquine (CQ), which inhibits lysosome-mediated degradation. Cotreatment with $\mathrm{MPP}^{+}$and CQ did not further increase LC3-II levels compared with CQ treatment alone (Fig. 3a, lanes 4 and 5; Fig. 3b), suggesting that $\mathrm{MPP}^{+}$-induced accumulation of LC3-II was not due to an increase in the production of LC3-II. Instead, $\mathrm{MPP}^{+}$-induced accumulation of LC3-II appeared to be caused by impaired autophagic degradation, as there was no synergistic effect between CQ and $\mathrm{MPP}^{+}$. However, CQ increased LC3-II levels in cells co-treated with $\mathrm{MPP}^{+}$and BAPTA-AM (Fig. $3 a$, lanes 3 and 6 ), indicating that there is no blockage in autophagic flux when cytosolic $\mathrm{Ca}^{2+}$ is buffered. We observed these autophagic events using endogenous autophagic marker LC3; however, another widely used autophagic substrate, p62, did not exhibit a similar trendtotal cellular p62 levels were unaffected by $\mathrm{MPP}^{+}$(Fig. 3a, c). Co-immunofluorescence studies showed that the cytosolic p62 puncta largely co-localized with LC3 puncta in $\mathrm{MPP}^{+}$-treated cells (Fig. 3d and Fig. S4). In MN9D cells cotreated with $\mathrm{MPP}^{+}$and BAPTA-AM, p62 puncta were markedly reduced (Fig. 3e), suggesting that the levels of the insoluble form of p62 were reduced after BAPTA-AM cotreatment. p62 is an autophagic adaptor protein that can bind to LC3 and ubiquitin ( $\mathrm{Ub})$ simultaneously, thereby linking ubiquitinated targets to autophagosomes ${ }^{36}$. Indeed, immunofluorescence studies revealed that p62-positive and Ub-positive puncta co-localized in the cytosol in response 

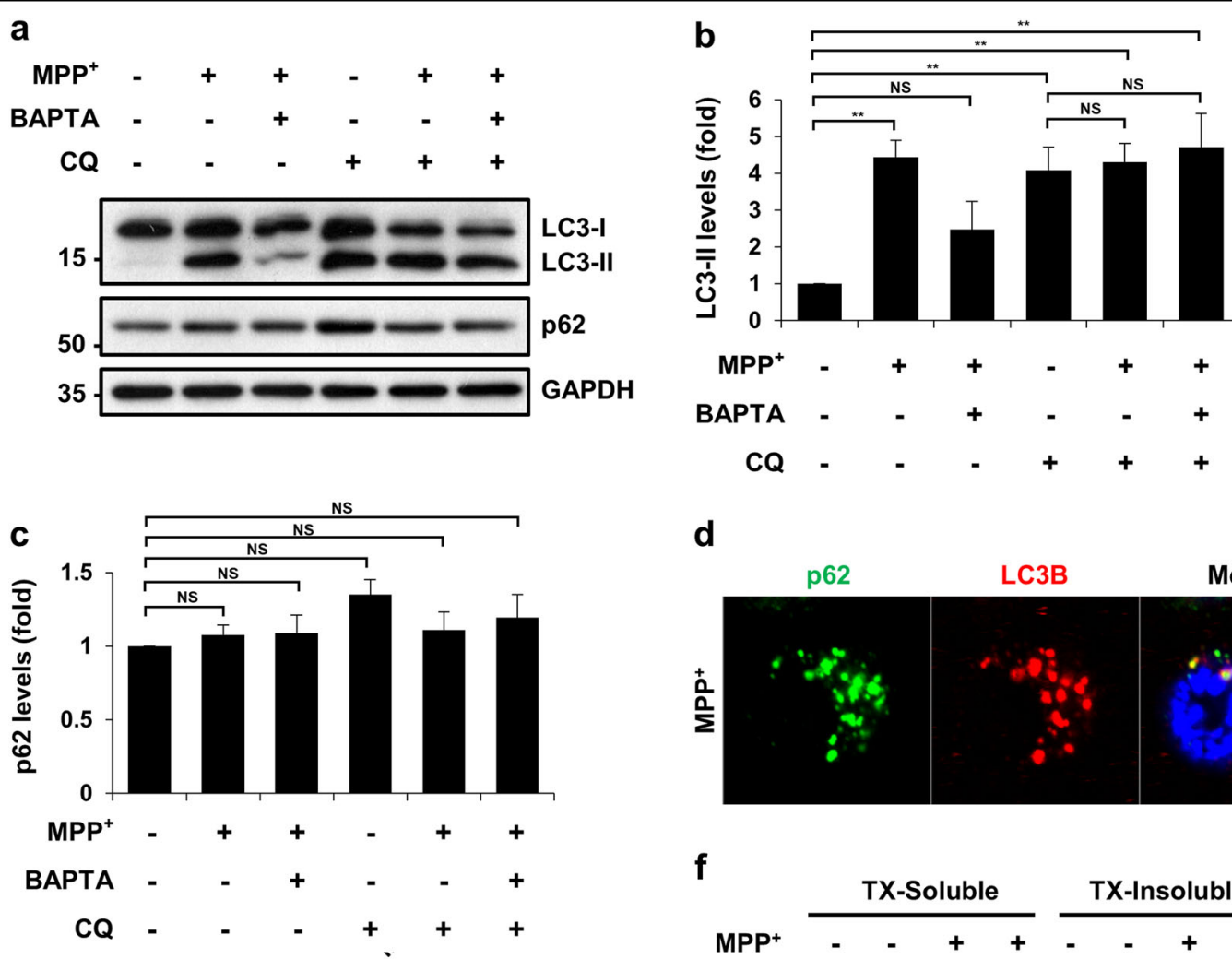

d

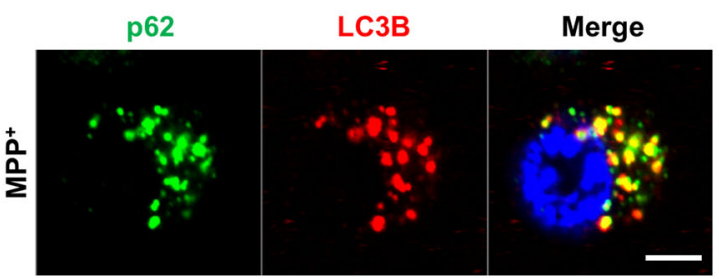

e

p62

Ub

Merge

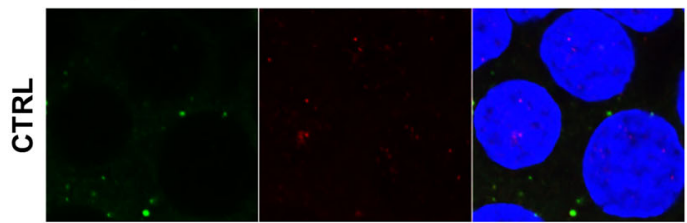

$\mathbf{f}$

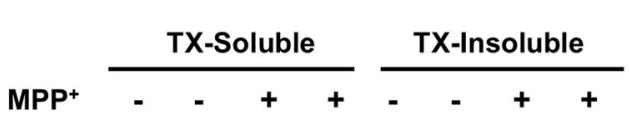

BAPTA - $+\quad-\quad+\quad-\quad+\quad-\quad+$
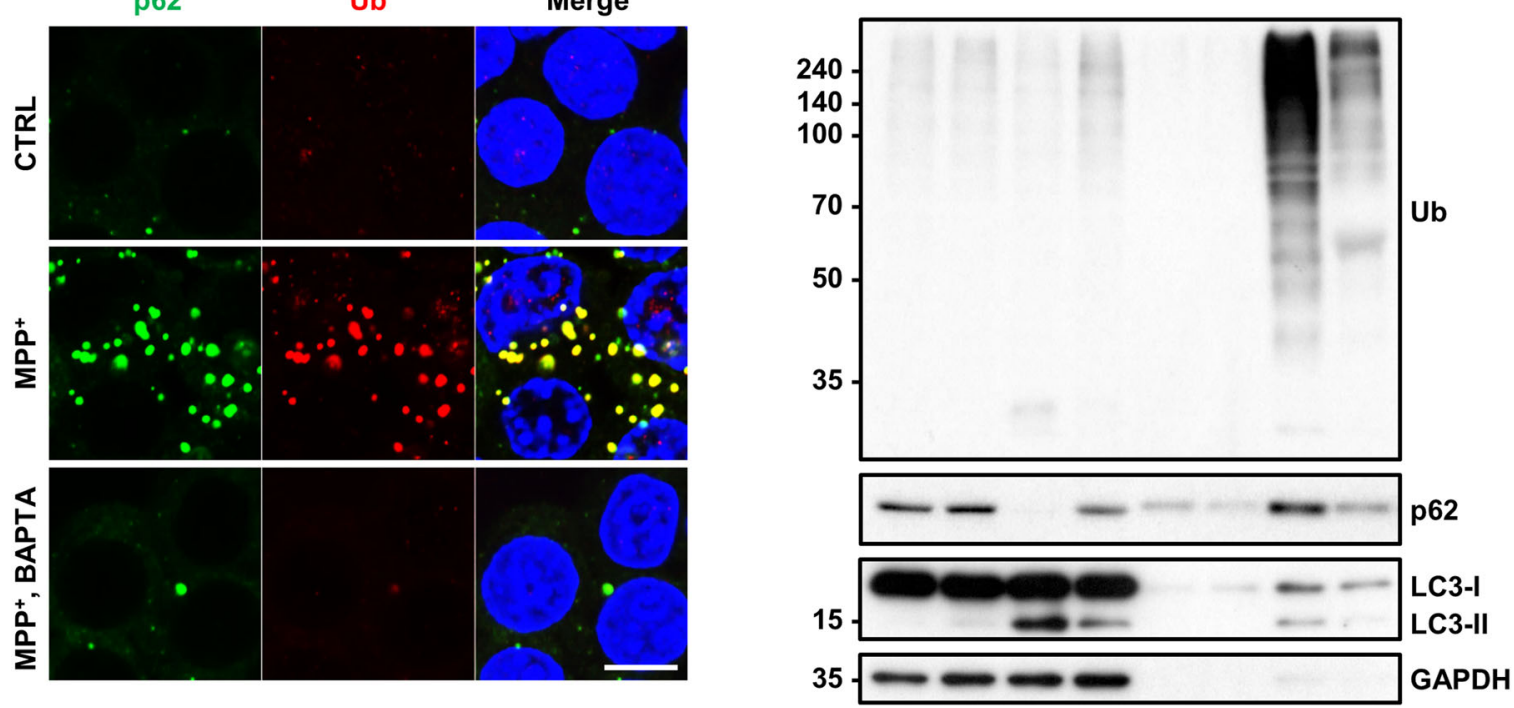

Fig. $3 \mathrm{MPP}^{+}$blocks autophagic flux as determined by an elevated calcium-dependent accumulation of insoluble p62 and Ub-positive spots. MN9D cells were treated with $50 \mu \mathrm{M} \mathrm{MPP}^{+}$in the presence or absence of $30 \mu \mathrm{M}$ BAPTA-AM and/or $50 \mu \mathrm{M}$ chloroquine (CQ) for $30 \mathrm{~h}$. a Immunoblot analyses were performed using the anti-LC3 or anti-p62 antibody. b, c Quantification of LC3-II and p62 levels in each condition was performed after normalization to GAPDH loading control. Bars represent the mean \pm SEM of three independent experiments. ${ }^{* *} p<0.01 ;$ NS, not significant. After $\mathrm{MPP}^{+}$treatment alone (d) or in combination with BAPTA-AM (e), cells were analyzed for the immunofluorescent localization of p62 (green) and LC3B (red) or ubiquitin ( $\mathrm{Ub}$; red). Cells were then examined using a confocal microscope. Merged views are provided in the right panel. The scale bar represents (d) $5 \mu \mathrm{m}$ and (e) $10 \mu \mathrm{m}$. f A representative immunoblot analyses of p62, ubiquitin, and LC3 in Triton X-100 (TX)-soluble or TXinsoluble fractions 
to $\mathrm{MPP}^{+}$treatment (Fig. 3e). These p62-positive $\mathrm{Ub}$ aggregates were not easily detected in cells co-treated with $\mathrm{MPP}^{+}$and BAPTA-AM (Fig. 3e). To confirm this result, we carried out a $1 \%$ Triton X-100 soluble/insoluble fractionation experiment and found that $\mathrm{MPP}^{+}$changed the solubility of p62 from the soluble to the insoluble fraction (Fig. 3f; compared with Fig. 3a, c). Consistent with the immunofluorescence data, immunoblot analyses indicated that ubiquitinated proteins accumulated in insoluble fractions following $\mathrm{MPP}^{+}$treatment. Co-treatment with $\mathrm{MPP}^{+}$and BAPTA-AM inhibited $\mathrm{MPP}^{+}$-induced accumulation of ubiquitinated proteins in the insoluble fraction. Taken together, these results indicate that $\mathrm{MPP}^{+}$treatment impairs autophagic flux, causing the accumulation of p62 and ubiquitinated proteins in the undegraded autophagosomes; however, the buffering of cytosolic $\mathrm{Ca}^{2+}$ can normalize the autophagic flux.

To verify the correlation between increased cytosolic $\mathrm{Ca}^{2+}$ levels and impairment of autophagic flux, we used another cell death paradigm in which nigericin induces impairment of autophagic flux in MN9D cells ${ }^{26}$. Nigericininduced surge of cytosolic $\mathrm{Ca}^{2+}$ was attenuated by BAPTA-AM (Fig. S5a). Nigericin-induced cell death was significantly suppressed by co-treatment with BAPTA-AM (Fig. S5b). Nigericin-induced accumulation of autophagic vacuoles was significantly inhibited in the presence of BAPTA-AM (Fig. S5c). Consistent with ultrastructural observations, immunoblot analyses showed that nigericininduced increase in LC3-II levels were blocked by BAPTAAM (Fig. S6a). Immunofluorescence studies indicated that co-treatment with nigericin and CQ did not further increase in the number and area of LC3 puncta compared with nigericin alone (Fig. S6b). However, CQ increased in the number and area of LC3 puncta in cells co-treated with nigericin and BAPTA-AM (Fig. S6b), supporting the notion that there is no blockage in autophagic flux when cytosolic $\mathrm{Ca}^{2+}$ is buffered.

\section{Normalization of cytosolic $\mathrm{Ca}^{2+}$ levels reverses the lysosomal pH deficits and impeded autophagic degradation caused by MPP ${ }^{+}$}

To explore the cause of impeded autophagic degradation by $\mathrm{MPP}^{+}$, we tested whether the number of lysosomes were affected by $\mathrm{MPP}^{+}$. The protein levels of LAMP-1 were not altered by treatment with $\mathrm{MPP}^{+}$alone or in combination with BAPTA-AM (Fig. 4a, b). Immunofluorescence analyses showed that the cellular distribution of LAMP-1 was unaltered in all the groups (Fig. 4c). The levels of Rab5 and Rab7 remained unchanged regardless of drug treatment, indicating that $\mathrm{MPP}^{+}$did not influence the distribution of the individual components of the endosomal pathway, including lysosomes. To study the effect of $\mathrm{MPP}^{+}$treatment on autophagosome- lysosome fusion ${ }^{37}$, we analyzed the co-localization of LC3 with LAMP-1. Cells treated with Torin-1, an mTOR inhibitor exhibited a similar degree of co-localization between LC3 and LAMP-1 when compared with MN9D cells treated with $\mathrm{MPP}^{+}$(Fig. 4d, e). Similarly, expression levels of other autophagosome-lysosome fusion markers, including syntaxin-17, p150Glued, and dynein intermediate chain was not altered regardless of $\mathrm{MPP}^{+}$treatment (Fig. S7), demonstrating that $\mathrm{MPP}^{+}$did not affect the fusion step between autophagosomes and lysosomes.

Optimal function of lysosomal hydrolases requires lysosomes to maintain a low internal $\mathrm{pH}^{37}$. To check whether the luminal $\mathrm{pH}$ of lysosomes was altered by $\mathrm{MPP}^{+}$treatment, MN9D cells were stained with LysoTracker Red. In comparison with DMSO-treated cells, $\mathrm{MPP}^{+}$-treated cells lost fluorescence (Fig. 4f, g). Because there were no changes in the number of lysosomes, these results suggested that the luminal acidity was altered in $\mathrm{MPP}^{+}$-treated cells. Notably, co-treatment with $\mathrm{MPP}^{+}$ and BAPTA-AM did not elevate the lysosomal $\mathrm{pH}$. To confirm $\mathrm{MPP}^{+}$-mediated elevation of lysosomal $\mathrm{pH}$, we performed a fluorogenic activity assay for cathepsin B, a major lysosomal protease. Treatment with bafilomycin A1, an inhibitor of lysosomal acidification, showed that the elevation of lysosomal $\mathrm{pH}$ led to decreased activity of cathepsin B (Fig. S8). Along with an elevated lysosomal $\mathrm{pH}$, cathepsin $\mathrm{B}$ activity was diminished by $\mathrm{MPP}^{+}$treatment, which implied that autophagic degradation was defective. Buffering of cytosolic $\mathrm{Ca}^{2+}$ with BAPTA-AM restored normal cathepsin $\mathrm{B}$ activity in $\mathrm{MPP}^{+}$-treated cells. To provide additional evidence for lysosomal neutralization and resultant impaired autophagy following $\mathrm{MPP}^{+}$treatment, we monitored autophagic flux by transiently expressing a tandom fluorescent-tagged LC3 probe (mRFP-EGFP-LC3), as described ${ }^{38}$. Under control conditions, yellow (red+/green + ) puncta were barely seen, and approximately $20 \%$ red (red+/green-) puncta were observed (Fig. 4h, i), suggesting that basal autophagy was operational, because most autophagosomes fused with lysosomes and were degraded due to low $\mathrm{pH}$ conditions. In contrast, in $\mathrm{MPP}^{+}$-treated cells, the numbers of redonly puncta were remarkably decreased and the numbers of yellow puncta increased. Because autophagosomelysosome fusion is not impaired, these findings support the view that $\mathrm{MPP}^{+}$interferes with lysosomal acidity, which prevents the quenching of GFP fluorescence. MN9D cells treated with $\mathrm{MPP}^{+}$and BAPTA-AM showed a similar pattern to DMSO-treated control cells. Therefore, our data suggest that lysosomes fail to keep the luminal $\mathrm{pH}$ low in response to $\mathrm{MPP}^{+}$treatment, which interrupts autophagic degradation; normalization of cytosolic $\mathrm{Ca}^{2+}$ levels reverses the lysosomal $\mathrm{pH}$ deficits caused by $\mathrm{MPP}^{+}$. 


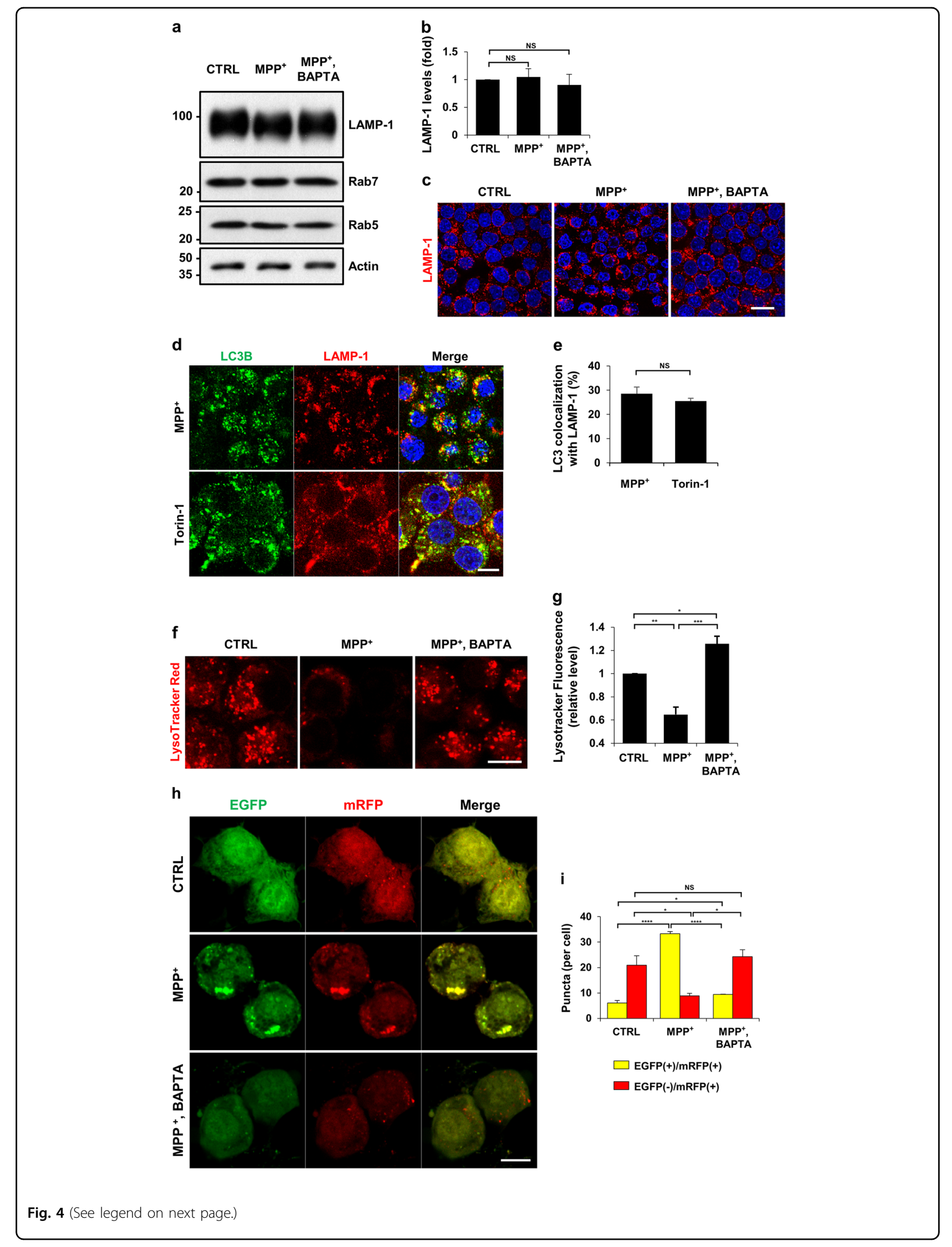


(see figure on previous page)

Fig. $4 \mathrm{MPP}^{+}$-induced impairment of autophagic degradation results from lysosomal malfunction in a calcium-dependent manner. a-c MN9D cells were treated with $50 \mu \mathrm{M} \mathrm{MPP}^{+}$alone or in combination with $30 \mu \mathrm{M}$ BAPTA-AM for $30 \mathrm{~h}$. a Cell lysates were subjected to immunoblot analyses with the indicated antibodies. b Quantification of LAMP-1 expression was performed after normalization to actin loading control. Bars represent the mean \pm SEM of three independent experiments. NS, not significant. $\mathbf{c}$ After drug treatment, cells were immunostained with anti-LAMP1 antibody. Representative confocal images are provided. Scale bar represents $20 \mu \mathrm{m}$. d, e MN9D cells were incubated with $50 \mu \mathrm{M} \mathrm{MPP}+$ for $30 \mathrm{~h}$ or $500 \mathrm{nM}$ Torin- 1 for $24 \mathrm{~h}$ and then immunostained using anti-LC3 and anti-LAMP-1 antibodies. The scale bar represents $10 \mu \mathrm{m}$. e Co-localization of LC3 with LAMP-1 in cells was quantified using ImageJ. Confocal images of at least 30 randomly selected cells from each of the three independent experiments were used for quantitation. Spots that were positive for both LC-3 and LAMP-1 were counted and expressed as a percentage of all LC3positive spots (100\%). Bars represent the mean \pm SEM of three independent experiments. NS, not significant. $\mathbf{f}, \mathbf{g}$ MN9D cells that were treated with $50 \mu \mathrm{M} \mathrm{MPP}+$ alone or in combination with $30 \mu \mathrm{M}$ BAPTA-AM for $30 \mathrm{~h}$ were stained with LysoTracker Red. Representative confocal images are provided. The scale bar represents $10 \mu \mathrm{m}$. g For quantitation, cells were subjected to flow cytometry. Data represent the fluorescence intensity relative to that of control cells (value $=1$ ). Bar represents the mean \pm SEM of three independent experiments. ${ }^{*} p<0.05 ;{ }^{* *} p<0.01 ;{ }^{* * *} p<0.001$. $\mathbf{h}$ MN9D cells were transfected with mRFP-EGFP-tagged LC3B probe for $24 \mathrm{~h}$ and treated with $50 \mu \mathrm{M} \mathrm{MPP}{ }^{+}$alone or in combination with $30 \mu \mathrm{M}$ BAPTAAM for $30 \mathrm{~h}$. After fixation, fluorescent images were acquired using confocal microscopy. The scale bar represents $10 \mu \mathrm{m}$. i Quantification of the number of yellow puncta (mRFP ${ }^{+}$EGFP $^{+}$-LC3B) and red puncta $\left(\mathrm{mRFP}^{+}-\mathrm{EGFP}^{-}\right.$-LC3B) were performed using at least 50 cells per condition. Bar represents the mean \pm SEM of three independent experiments. ${ }^{*} p<0.05 ;{ }^{* * * *} p<0.0001$; NS, not significant

Lowering cytosolic $\mathrm{Ca}^{2+}$ levels has a neuroprotective effect on $\mathrm{MPP}^{+}$-mediated cytotoxicity, independent of $\mathrm{mTOR}$ activity but dependent on lysosomal activity

Elevated cytosolic $\mathrm{Ca}^{2+}$ levels promote autophagy via the calcium/calmodulin-dependent protein kinase (CaMK)- $\beta$-AMP-activated protein kinase (AMPK)-mammalian target of rapamycin (mTOR) pathway ${ }^{39}$. To explore whether $\mathrm{MPP}^{+}$-induced cytosolic $\mathrm{Ca}^{2+}$ elevation regulates mTOR signaling in MN9D cells, we measured mTOR activity by checking the phosphorylation status of mTOR and p70S6K. Immunoblotting analyses showed that the levels of $\mathrm{p}$-mTOR and p-p70S6K were reduced after $24 \mathrm{~h}$ of $\mathrm{MPP}^{+}$incubation, whereas $\mathrm{MPP}^{+}$-induced reduction was restored in MN9D cells co-treated with $\mathrm{MPP}^{+}$and BAPTA-AM (Fig. 5a). To investigate whether mTOR signaling is required for the neuroprotective effect conferred by the buffering of cytosolic $\mathrm{Ca}^{2+}$, MN9D cells were treated with $\mathrm{MPP}^{+}$in the presence or absence of rapamycin, an mTOR inhibitor. The addition of rapamycin in $\mathrm{MPP}^{+}$-treated cells failed to further increase LC3-II levels (Fig. 5b, lanes 3 and 4) and had no impact on cell viability (Fig. 5c, lanes 1 and 2). In MN9D cells treated with $\mathrm{MPP}^{+}$and BAPTA-AM, cell viability remained unaffected regardless of rapamycin treatment (Fig. 5c, lanes 3 and 4). Similarly, no significant reduction in cell viability was caused by rapamycin in MN9D cells overexpressing calbindin-D28K (MN9D/CB; Fig. S9a). Collectively, these data demonstrate that cytosolic $\mathrm{Ca}^{2+}$ elevation by $\mathrm{MPP}^{+}$inactivates mTOR signaling. However, the lowering of cytosolic $\mathrm{Ca}^{2+}$ levels had a protective effect on $\mathrm{MPP}^{+}$toxicity, which was independent of mTOR activity.

Next, we addressed whether lysosomal integrity was critical for $\mathrm{Ca}^{2+}$-mediated cell protection against $\mathrm{MPP}^{+}$mediated neurotoxicity. Hence, we analyzed the viability of cells treated with $\mathrm{MPP}^{+}$alone or in combination with
BAPTA-AM, in the presence or absence of CQ. CQ did not influence the cell viability of $\mathrm{MPP}^{+}$-treated cells (Fig. $5 \mathrm{~d})$. However, CQ decreased the viability of cells cotreated with $\mathrm{MPP}^{+}$and BAPTA-AM to a level similar to that of cells treated with $\mathrm{MPP}^{+}$alone. Consistent with this, the protective effect of calbindin-D28K on $\mathrm{MPP}^{+}$ toxicity was dependent on lysosomal functionality (Fig. $\mathrm{S} 9 \mathrm{~b})$. Mitochondrial dysfunction is one of the most characteristic features of $\mathrm{MPP}^{+}$-induced neurodegeneration. Mitochondrial staining with MitoTracker Red revealed that $\mathrm{MPP}^{+}$treatment resulted in the loss of mitochondrial membrane potential (MMP), but not when cytosolic $\mathrm{Ca}^{2+}$ levels were buffered with BAPTA-AM (Fig. 5 e, upper panels). Moreover, we observed that the addition of CQ disrupted MMP in cells co-treated with $\mathrm{MPP}^{+}$ and BAPTA-AM, suggesting that autophagy-lysosomal degradation is required for mitochondrial integrity under conditions of $\mathrm{MPP}^{+}$and BAPTA-AM co-treatment (Fig. 5e, lower panels). Treatment with $\mathrm{CQ}$ alone did not depolarize mitochondria, suggesting that lysosomal deficits may be insufficient for mitochondrial rupture. These findings imply that under normal conditions, defective lysosomes are tolerated by cells: however, because $\mathrm{MPP}^{+}$ disrupts mitochondria by inhibiting the mitochondrial electron transport complex I, lysosomal activity and subsequent functional autophagic processes become crucial for preserving healthy mitochondria and maintaining cell viability in cells treated with $\mathrm{MPP}^{+}$and BAPTA-AM.

\section{Buffering of cytosolic $\mathrm{Ca}^{2+}$ suppresses autophagosome accumulation and lysosomal $\mathrm{pH}$ neutralization in $\mathrm{MPP}^{+}$- treated mouse cortical neurons}

To validate our data obtained from MN9D cells, primary cultures of cortical neurons were treated with $\mathrm{MPP}^{+}$. Fluo-3 fluorescence staining showed that $\mathrm{MPP}^{+}$ 

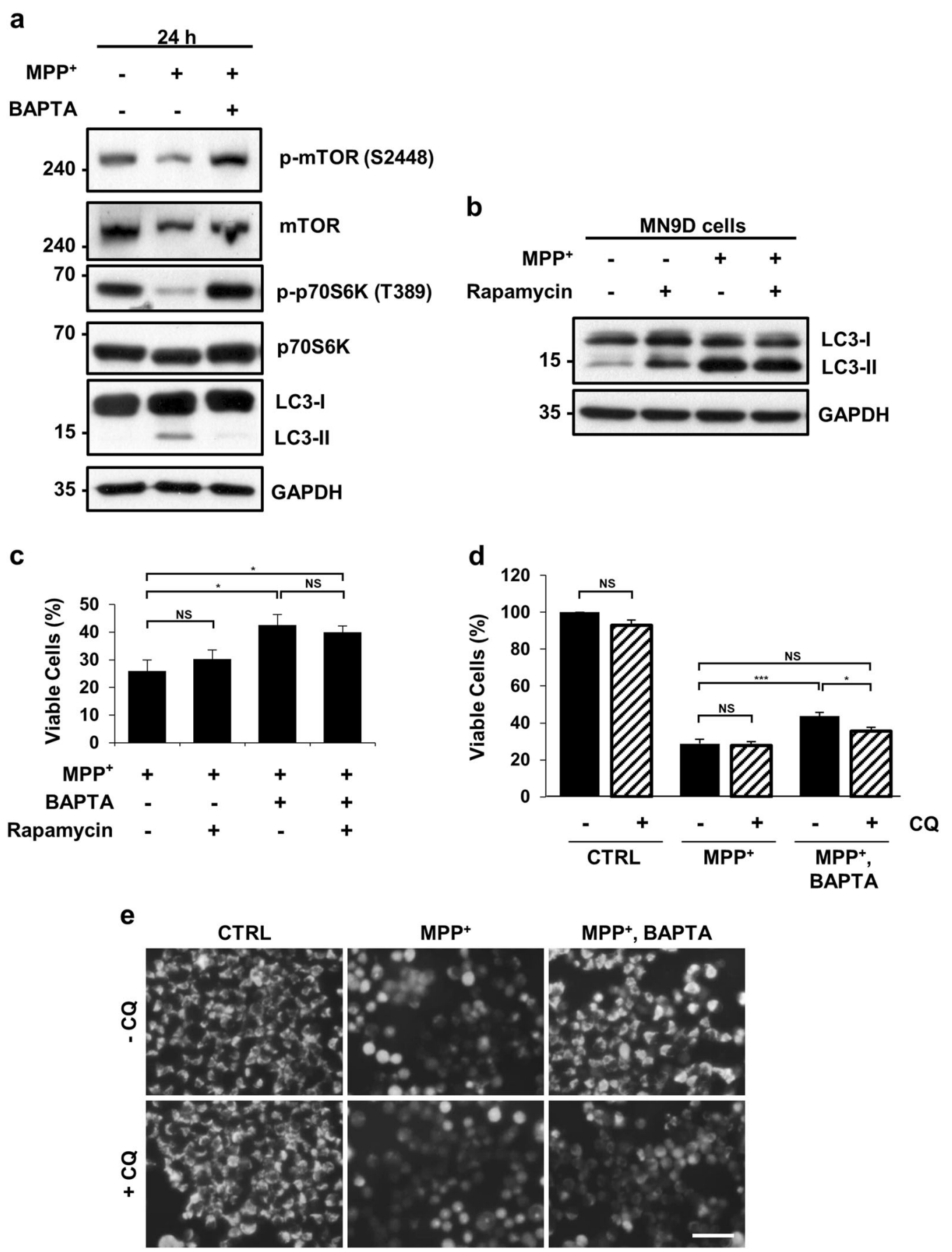

MPP $^{+}$, BAPTA

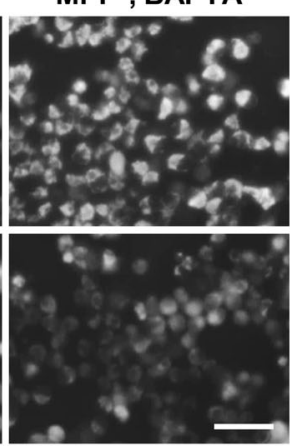

Fig. 5 Lysosomal activity is essential for calcium-mediated cell protection against MPP $^{+}$toxicity. a MN9D cells were treated with $50 \mu M M^{2} P^{+}$ in the presence or absence of $30 \mu \mathrm{M}$ BAPTA-AM for $24 \mathrm{~h}$. Cell lysates were subjected to immunoblot analyses using the indicated antibodies. Representative blots are provided. MN9D cells were treated with $50 \mu \mathrm{M} \mathrm{MPP}{ }^{+}$in the presence or absence of $30 \mu \mathrm{M}$ BAPTA-AM plus b, c $750 \mathrm{nM}$ rapamycin or $\mathbf{d}$, e $50 \mu \mathrm{M}$ CQ for $30 \mathrm{~h}$. (b) LC3-II levels were detected by immunoblotting with anti-LC3B antibodies. c, d MTT reduction assays were performed to assess cell viability expressed as a percentage of the untreated control cells (100\%). Bars represent the mean \pm SEM of three independent experiments in triplicate. ${ }^{*} p<0.05 ;{ }^{* * *} p<0.001$; NS, not significant. e After treatment with the indicated combination of drugs, MN9D cells were stained with $0.75 \mu \mathrm{M}$ MitoTracker Red CMXRos and imaged using fluorescence microscopy. The scale bar represents $200 \mu \mathrm{m}$ 
treatment caused a surge in cytosolic $\mathrm{Ca}^{2+}$ levels in cortical neurons (Fig. 6a). The calcium-activated calpaincleaved form of fodrin was detected (Fig. 6b). Dosedependent increase in the LC3-II form was found. Addition of BAPTA-AM inhibited $\mathrm{MPP}^{+}$-induced cortical neuronal death, thus confirming the neuroprotective effect of buffering of cytosolic $\mathrm{Ca}^{2+}$ (Fig. 6c). Similarly, BAPTA-AM inhibited $\mathrm{MPP}^{+}$-induced accumulation of LC3-II (Fig. 6d, e). Interestingly, levels of LAMP-1 increased in cortical neurons treated with $\mathrm{MPP}^{+}$(Fig. $6 \mathrm{~d}, \mathrm{f}$ ). Addition of BAPTA-AM reduced the $\mathrm{MPP}^{+}$induced levels of LAMP-1, but these levels were still higher than those in untreated control cortical neurons. To determine lysosomal integrity in cortical neurons, lysosomal acidity was checked using the LysoTracker dye (Fig. 6g). Similar to cells treated with bafilomycin A1, cells treated with $\mathrm{MPP}^{+}$almost lost the fluorescence despite containing high levels of LAMP-1, thus indicating elevated lysosomal $\mathrm{pH}$. Functional lysosomes were preserved in cells co-treated with $\mathrm{MPP}^{+}$and BAPTA-AM. These data suggest that cytosolic $\mathrm{Ca}^{2+}$ buffering protects cortical neurons from $\mathrm{MPP}^{+}$-mediated cytotoxicity by restoring normal lysosomal $\mathrm{pH}$ and autophagic flux.

\section{Discussion}

Cytosolic $\mathrm{Ca}^{2+}$ is crucial for maintaining homeostasis of the nervous system by regulating neurotransmitter release and post-synaptic activity. Dysregulation of cytosolic $\mathrm{Ca}^{2+}$ is linked to pathological neurodegeneration ${ }^{40-43}$. Recent evidence implicates $\mathrm{Ca}^{2+}$ in the pathogenesis of $\mathrm{PD}$ and the regulation of $\mathrm{Ca}^{2+}$ may comprise a potential therapeutic target for neuroprotection in $\mathrm{PD}^{44-46}$. Among many hypotheses proposed to explain selective vulnerability of dopaminergic neurons in the $\mathrm{SNpc}$, the maintenance of cytosolic $\mathrm{Ca}^{2+}$ homeostasis has drawn much attention $^{47}$. Dopaminergic neurons in this region harbor the $\mathrm{Ca}^{2+}$-binding protein, calbindin-D28k that can buffer cytosolic $\mathrm{Ca}^{2+, 48}$, thus substantiating the role of cytosolic $\mathrm{Ca}^{2+}$ buffering in PD pathogenesis. Interestingly, calbindin- D28K-positive neurons of SNpc are relatively preserved in PD postmortem samples and in monkey and mouse PD models, which were produced by the administration of the neurotoxin, $\mathrm{MPTP}^{48-52}$. Similarly, the membrane permeable $\mathrm{Ca}^{2+}$ chelator, BAPTA-AM, significantly protects cells from oxidative stress ${ }^{53}$. Preloading of BAPTA-AM and a calcium channel blocker suppress alpha-synuclein aggregates in HEK293T cells and SHSY$5 \mathrm{Y}$ cells treated with $\mathrm{KCl}^{54}$, supporting the notion that dysregulation of cytosolic $\mathrm{Ca}^{2+}$ contributes to dopaminergic neurodegeneration. Although studies involving the ectopic expression of calbindin-D28K and co-treatment with BAPTA-AM have provided additional evidence for the potential neuroprotective effects of cytosolic $\mathrm{Ca}^{2+30-32}$, the underlying mechanism remains to be determined.
We have demonstrated that $\mathrm{MPP}^{+}$induces $\mathrm{Ca}^{2+}$ dependent cell death in the MN9D cells and primary cultures of cortical and mesencephalic neurons ${ }^{22,24,55-59}$. Consequently, overexpression of calbindin-D28K or cotreatment with BAPTA-AM prevents $\mathrm{MPP}^{+}$-induced cell death $^{32}$. $\mathrm{MPP}^{+}$-induced cell death is not accompanied by biochemical and morphological features typical of apoptosis. Rather, autophagic processes is involved in $\mathrm{MPP}^{+}$ toxicity ${ }^{25,26}$. Our present study provides novel insights into the mechanism underlying the neuroprotective effects of calcium buffering in the experimental PD models. Here, we demonstrated that $\mathrm{MPP}^{+}$-induced autophagic alterations were a consequence of impaired autophagic degradation resulting from increased lysosomal pH. Buffering of cytosolic $\mathrm{Ca}^{2+}$ by BAPTA-AM cotreatment or by the overexpression of calbindin D28K preserved physiological lysosomal $\mathrm{pH}$ and thereby, lysosomal activity. Therefore, inhibition of a drug-induced surge of cytosolic $\mathrm{Ca}^{2+}$ is crucial for maintaining autophagic flux, eventually preventing $\mathrm{MPP}^{+}$toxicity. Typical pathological features of $\mathrm{PD}$, namely abnormal protein aggregation and mitochondrial rupture, seemed to be relieved by lowering cytosolic $\mathrm{Ca}^{2+}$ elevation. Taken together, our study raises the possibility that lysosomal integrity plays a crucial role in preventing $\mathrm{MPP}^{+}$-induced neuronal death.

$\mathrm{Ca}^{2+}$ is an autophagy modulator, but its effects show duality, necessitating further interpretation ${ }^{60}$. For example, based on the findings that inhibition of inositol 1,4,5triphosphate receptors $\left(\mathrm{IP}_{3} \mathrm{Rs}\right)$ promotes autophagy ${ }^{61,62}$, it has been suggested that $\mathrm{Ca}^{2+}$ suppresses autophagy. In contrast, elevation of cytosolic $\mathrm{Ca}^{2+}$ stimulates autophagy via the CaMKK $\beta$-AMPK-mTOR pathway ${ }^{39}$. In addition, calcineurin is required for the nuclear translocation of transcription factor EB (TFEB), triggering autophagy and lysosomal biogenesis ${ }^{63}$. Here, we observed that elevated cytosolic $\mathrm{Ca}^{2+}$ correlated with mTOR signaling in $\mathrm{MPP}^{+}$treated cells, without apparent promotion of autophagy. Rather, $\mathrm{MPP}^{+}$-induced elevation cytosolic $\mathrm{Ca}^{2+}$ elevation was associated with autophagy impairment, causing lysosomal defects. In support of this argument, we demonstrated that lysosomal $\mathrm{pH}$ is increased by $\mathrm{MPP}^{+}$in a $\mathrm{Ca}^{2+}$-dependent way. Lysosomal membrane permeabilization (LMP) upon $\mathrm{MPP}^{+}$treatment is a cause of elevated lysosomal $\mathrm{pH}^{33}$. Meanwhile, cytosolic $\mathrm{Ca}^{2+}$ overload may lead to the continuous use of ATP by $\mathrm{Ca}^{2+}$ ATPases in an attempt to remove $\mathrm{Ca}^{2+}$ from the cytosol, thus depleting intracellular ATP. Because lysosomal acidification is conducted by v-ATPases, which pump protons into lysosomes using the energy from ATP hydrolysis, lowered ATP levels can cause incomplete acidification of the lysosomal lumen. In line with this possibility, we found that the protein levels of TFEB were diminished by $\mathrm{MPP}^{+}$, but not by $\mathrm{MPP}^{+}$and BAPTA-AM 


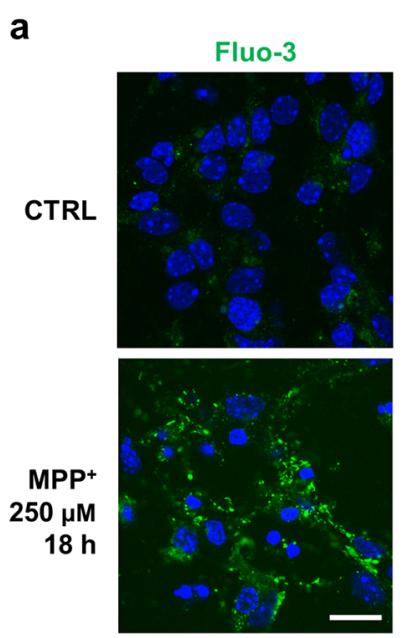

b
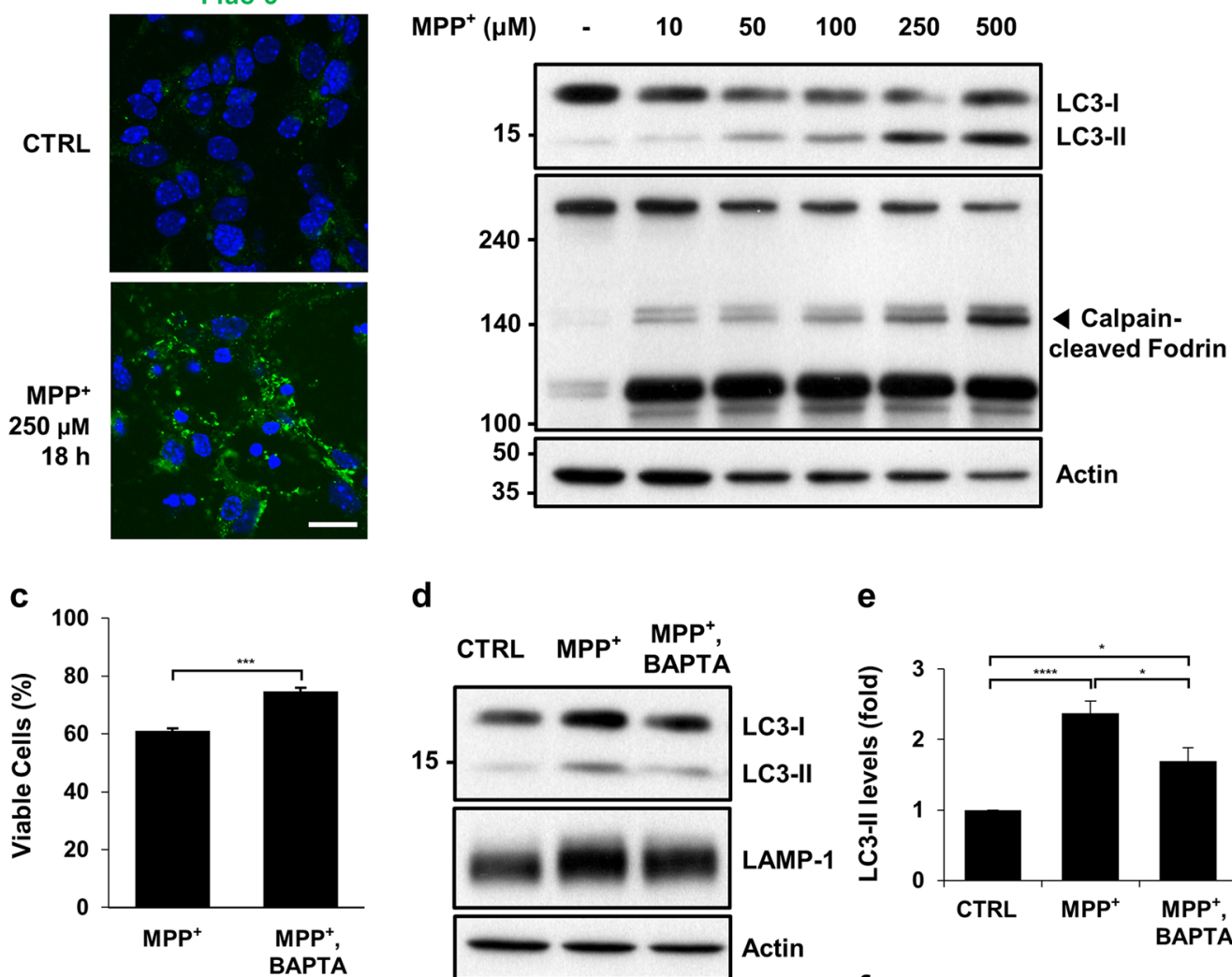

d

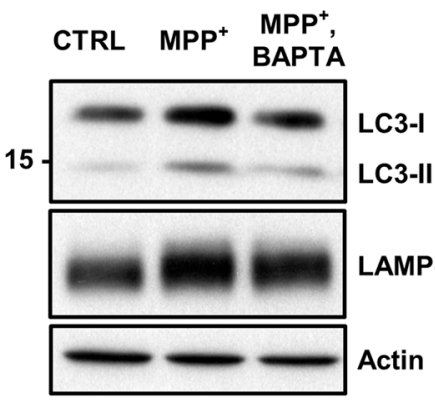

e

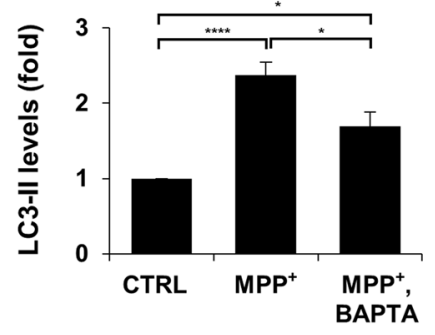

$\mathbf{f}$

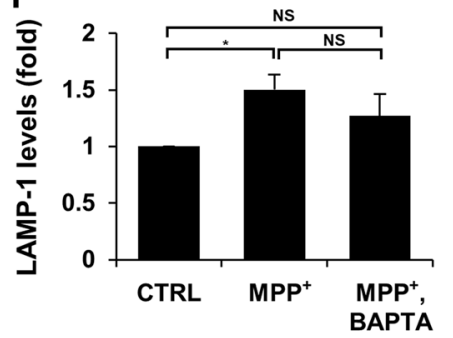

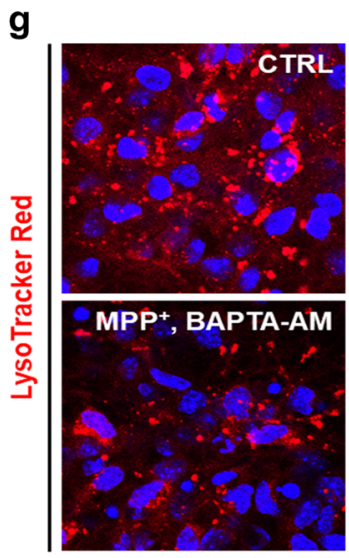

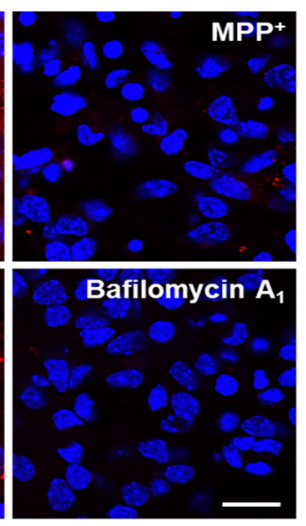

Fig. 6 Buffering of cytosolic calcium suppresses cell death, LC3-II accumulation and lysosomal pH elevation in MPP ${ }^{+}$-treated cortical neurons. a Primary cultures of cortical neurons prepared from the cortices of E14.5 mouse embryos were treated with or without $250 \mu \mathrm{M} \mathrm{MPP}{ }^{+}$for $18 \mathrm{~h}$. Cells were then loaded with $3 \mu \mathrm{M}$ Fluo-3 and subjected to counterstaining with Hoechst dye. Fluorescent images were taken using a confocal microscopy. The scale bar represents $20 \mu \mathrm{m}$. b Cortical neurons were incubated with the indicated concentrations of MPP ${ }^{+}$for $24 \mathrm{~h}$. Cell lysates were subjected to immunoblot analyses using anti-LC3 or anti-fodrin antibody. Anti-actin antibody was used as a loading control. c- $\mathbf{g}$ Cortical neurons were treated with $250 \mu \mathrm{M} \mathrm{MPP}{ }^{+}$alone in combination with $0.5 \mu \mathrm{M}$ BAPTA-AM for $18 \mathrm{~h}$. c Cells were subjected to the MTT assay. Cell viability was expressed as a percentage of $\mathrm{MPP}^{+}$- treated cells compared to the untreated control cells (100\%). Bar represents the mean \pm SEM of three independent experiments in triplicate. ${ }^{* * *} p<0.001$. $\mathbf{d}-\mathbf{f}$ Cell lysates were analyzed using immunoblotting with anti-LC3 or anti-LAMP-1 antibodies. The intensity of (e) LC3-II signals or (f) LAMP-1 from each condition was densitometrically measured using Image J. After normalization to the intensity of the actin signal, values were expressed as a fold change relative to the untreated control $(v a l u e=1)$. Bars represent the mean \pm SEM of four independent experiments. ${ }^{*} p<0.05 ;{ }^{* * * *} p<0.0001$; NS, not significant. g Cortical neurons were treated with the indicated drugs. For comparison, cells were treated with $10 \mathrm{nM}$ bafilomycin $\mathrm{A}_{1}$ for $4 \mathrm{~h}$, stained with LysoTracker Red, and counterstained with Hoechst dye. Cells were then imaged using confocal microscopy. Representative fluorescent images are provided. The scale bar represents $20 \mu \mathrm{m}$ 
co-treatment (unpublished data). Given that v-ATPase subunits are targets of $\mathrm{TFEB}^{64}$, we believe the $\mathrm{Ca}^{2}$ ${ }^{+}$-dependent decrease in TFEB protein levels may contribute to the neutralization of lysosomal $\mathrm{pH}$ by influencing v-ATPases. Using the MitoTracker Red staining and the MTT reduction assays, we showed that cytosolic $\mathrm{Ca}^{2+}$ buffering prevents loss of $\mathrm{MPP}^{+}$-induced mitochondrial membrane potential and cell death, respectively. However, we found that this protective effect was abrogated when CQ inhibited lysosomal degradation (Fig. 5). Because CQ treatment does not lead to mitochondrial depolarization or decreased cell viability, lysosomal deficits may be insufficient for mitochondrial rupture or cell death. These findings imply that under normal conditions, defective lysosomes are tolerated by cells; however, lysosomal activity and functional autophagy become crucial for preserving a pool of healthy mitochondria in $\mathrm{MPP}^{+}$treated cells. Under conditions in which mitochondria are damaged by treatment with $\mathrm{MPP}^{+}$, removing damaged mitochondria through mitophagy might be important for mitochondrial homeostasis. Therefore, the buffering of cytosolic $\mathrm{Ca}^{2+}$ may protect cells from $\mathrm{MPP}^{+}$toxicity by rescuing the autophagy-lysosome pathway.

Among several features that contributes to selective vulnerability of dopaminergic neurons in $\mathrm{SNpc}$, electrophysiological, epidemiological, and neuropathological studies have implicated that $\mathrm{Ca}^{2+}$ entry through Cav1 channels is amenable to phamacotherapy ${ }^{46}$. Consequently, accumulating evidence suggests that regulating cytosolic $\mathrm{Ca}^{2+}$ levels through these channels has a neuroprotective effect in animal models of $\mathrm{PD}^{45,46,65}$. For example, systemic administration of isradipine, a dihydropyridine antagonist of L-type $\mathrm{Ca}^{2+}$ channels, forces dopaminergic neurons in rodents to revert to a juvenile, $\mathrm{Ca}^{2+}$-independent mechanism to generate autonomous activity. More importantly, antagonist-induced reversion confers protection against dopaminergic neurotoxins. It is noteworthy that isradipine is currently being evaluated in a phase III clinical trial study for patients with early PD, showing that dysregulated $\mathrm{Ca}^{2+}$ homeostasis is an attractive potential target for PD drug development. Accordingly, our study may shed light on the mechanisms underlying future $\mathrm{Ca}^{2+}$-modulating therapies for $\mathrm{PD}$, highlighting the vital role of the autophagy-lysosome pathway.

\section{Materials and methods}

\section{Cell culture and drug treatment}

All experimental procedures were approved by the Institutional Animal Care and Use Committee of Yonsei University (permissions: IACUC 2017-10-647-01 and 2018-01-689-01). The MN9D neuronal cell line was established by somatic fusion between embryonic mesencephalic neurons and N18TG neuroblastoma ${ }^{28,29}$, and cultured as previously described ${ }^{25,26}$. Briefly, MN9D cells were grown at $37^{\circ} \mathrm{C}$ in Dulbecco's modified Eagle's medium (DMEM; Sigma-Aldrich, D5648) supplemented with $10 \%$ fetal bovine serum (FBS; Gibco, 26140-079) on culture dishes coated with $25 \mu \mathrm{g} / \mathrm{ml}$ poly-D-lysine (SigmaAldrich, P0899) in an atmosphere of $90 \%$ air and $10 \%$ $\mathrm{CO}_{2}$. MN9D cells were either left untreated or treated for the indicated time periods with $50 \mu \mathrm{M}$ 1-methyl-4phenylpyridinium (MPP ${ }^{+}$; Sigma-Aldrich, D048) alone or in combination with $30 \mu \mathrm{M}$ 1,2-Bis(2-aminophenoxy) ethane- $\mathrm{N}, \mathrm{N}, \mathrm{N}^{\prime}, \mathrm{N}^{\prime}$-tetraacetic acid tetrakis(acetoxymethyl ester) (BAPTA-AM; Life Technologies, B6769), $50 \mu \mathrm{M}$ chloroquine (CQ; Sigma-Aldrich, C6628), $25 \mathrm{nM}$ bafilomycin $\mathrm{A}_{1}$ (Sigma-Aldrich, B1793), $750 \mathrm{nM}$ rapamycin (Sigma-Aldrich, R-5000), or $500 \mathrm{nM}$ Torin-1 (Cell Signaling Technology, 14379). Concentrations and durations of drug treatment were empirically determined. Previously established MN9D stable cell lines overexpressing calbindin-D28 $\mathrm{K}^{32}$ were maintained in culture medium containing $250 \mu \mathrm{g} / \mathrm{ml} \mathrm{G418(A.G.} \mathrm{Scientific,} \mathrm{G1033).} \mathrm{For}$ preparing primary cultures of cortical neurons, cerebral cortices were removed from gestational day 14.5 mouse embryos (Orient, Gyeong-gi, Republic of Korea) and mechanically dissociated as previously described ${ }^{66}$. Briefly, dissociated cortical cells were plated at a density of $5 \times 10^{6}$ cells per well of six-well plates or at $1 \times 10^{6}$ cells per well of 24-well plates pre-coated with $100 \mu \mathrm{g} / \mathrm{mL}$ poly-D-lysine and $1 \mu \mathrm{g} / \mathrm{mL}$ laminin (Invitrogen, 23017015). Cortical neurons were incubated at $37^{\circ} \mathrm{C}$ in MEM (Gibco, 11090-081) containing 0.6\% glucose (Gibco, 15023-021), $1 \mathrm{mM}$ sodium pyruvate (Sigma, P5280), $2 \mathrm{mM}$ L-glutamine (Sigma, G8540), 100 units $/ \mathrm{ml}$ penicillin-streptomycin (Thermo Fisher Scientific, 15140122), and 10\% FBS in the atmosphere of $95 \%$ air and $5 \% \mathrm{CO}_{2}$. At $24 \mathrm{~h}$, culture medium was changed to Neurobasal medium (Invitrogen, 21103049) supplemented with 2\% B-27 (Gibco, 17504044), $0.5 \mathrm{mM}$ L-glutamine and $10 \mu \mathrm{M}$ cytosine $\beta$-D-arabinofuranoside (Ara-C, SigmaAldrich, C1768). At 4 days in vitro (DIV), cultures were treated with the indicated drugs that were dissolved in the same medium.

\section{Measurement and imaging of intracellular $\mathrm{Ca}^{2+}$}

Cells were stained with $3 \mu \mathrm{M}$ Fluo-3 (Life Technology, F1242) mixed with pluronic acid (Life Technology, P3000MP) for $30 \mathrm{~min}$ at $37^{\circ} \mathrm{C}$ and washed twice with DMEM. For flow cytometry, cells were trypsinized, and 20,000 cells per condition per experiment were analyzed using FACSCalibur and CellQuest (BD Biosciences). For obtaining fluorescent images, Fluo-3 loaded cells were mounted with Vectashield mounting medium (Vector Laboratories, H1000). Fluorescence images were acquired using a confocal microscope equipped with epifluorescence and a digital image analyzer (LSM 700, Carl Zeiss). 


\section{Cell viability assay}

Following drug treatment, the rate of cell viability was measured using the 3-(4,5-dimethylthiazol-2-yl)-2,5diphenyltetrazolium bromide (MTT) reduction assay, as described previously ${ }^{67}$. Briefly, cells cultured on 24-well plates were incubated with $1 \mathrm{mg} / \mathrm{ml}$ MTT solution (Sigma-Aldrich, M2128) at $37^{\circ} \mathrm{C}$ for $1 \mathrm{~h}$ and lysed for $18 \mathrm{~h}$ in an extraction buffer containing $20 \%$ sodium dodecyl sulfate (SDS) in 50\% aqueous dimethylformamide. The optical densities of formazan were measured at $590 \mathrm{~nm}$ and $650 \mathrm{~nm}$ as test and reference wavelengths, respectively, using a VICTOR ${ }^{\mathrm{m}}$ X5 Multilabel Plate Reader (PerkinElmer). Cell viability was expressed as a percentage relative to the value in untreated control (100\%).

\section{Transmission electron microscopy}

Electron microscopy was performed as previously described ${ }^{27}$. Briefly, MN9D cells grown in petri dishes were treated with $50 \mu \mathrm{M} \mathrm{MPP}{ }^{+}$alone or in combination with $30 \mu \mathrm{M}$ BAPTA-AM for $30 \mathrm{~h}$ followed by fixation with a mixture of $2 \%$ formaldehyde and $0.2 \%$ glutaraldehyde (Polysciences, Inc., 01909) in $0.1 \mathrm{M}$ cacodylate buffer ( $\mathrm{pH} \mathrm{7.2)}$ for $30 \mathrm{~min}$ at $37^{\circ} \mathrm{C}$. Free aldehyde groups were blocked for $1 \mathrm{~h}$ by soaking the cells in $50 \mathrm{mM}$ ammonium chloride in $0.1 \mathrm{M}$ cacodylate buffer. Cells were mechanically removed, sedimented by centrifugation, enclosed in liquefied $2 \%$ agarose, and then post-fixed for $1 \mathrm{~h}$ with $1 \%$ osmium tetroxide (Electron Microscopy Sciences, EMS, 19152) in distilled water. This step was followed by en bloc staining with $1 \%$ aqueous uranyl acetate for $1 \mathrm{~h}$. Cells were then subjected to dehydration in a graded ethanol series and embedded in Epon-Araldite (Fluka, Germany, 45345). Ultrathin sections ( $80 \mathrm{~nm}$ thickness) were prepared on cupper slot grids, stained with uranyl acetate and lead citrate, and observed at $80 \mathrm{kV}$ with a Hitachi H-7650 electron microscope (Hitachi). Electron micrographs were taken with an 11-megapixel CCD XR611-M digital camera (Advanced Microscopy Techniques).

\section{Immunoblot analyses and immunofluorescence staining}

At various times after drug treatment, cells were lysed on ice in phosphate-buffered saline (PBS; Lonza, 17517Q) containing $1 \%$ Triton X-100 (Sigma, T8787), 1\% SDS, and complete protease inhibitor cocktail (Roche, 1873580), and sonicated for homogenization. Cell lysates were centrifuged at $13,000 \times g$ for $15 \mathrm{~min}$ at $4{ }^{\circ} \mathrm{C}$. Supernatant proteins were collected and quantified using the Bradford protein assay reagent (Bio-Rad, 500-0006). For preparing Triton X-100 (TX)-soluble and -insoluble fraction, cells were lysed on ice in PBS containing 1\% Triton X-100 and complete protease inhibitor cocktail for $30 \mathrm{~min}$, and then homogenized using a 1-ml syringe with a 26 -gauge needle. After centrifugation at $15,000 \times g$ for
$30 \mathrm{~min}$ at $4{ }^{\circ} \mathrm{C}$, supernatants were collected as TX-soluble fractions. After four washes with PBS containing $1 \%$ Triton X-100, the pellets were resuspended in $8 \mathrm{M}$ urea buffer containing $1 \%$ SDS, $1 \%$ Triton X-100, and complete protease inhibitor, and sonicated. TX-insoluble fractions were collected by centrifugation at $15,000 \times g$ for $15 \mathrm{~min}$ at $4{ }^{\circ} \mathrm{C}$. Approximately $10-50 \mu \mathrm{g}$ of protein per sample was separated by electrophoresis on $8-15 \%$ SDSpolyacrylamide gels and transferred to polyvinylidene fluoride membranes (Pall Corp., 66543). Membranes were probed with primary antibodies overnight at $4{ }^{\circ} \mathrm{C}$ and washed with Tris-buffered saline containing $0.1 \%$ Tween20 (TBST). The following primary antibodies were used: rabbit anti-LC3 (Cell Signaling Technology, 2775), guinea pig anti-p62 (Progen, GP62-C), mouse anti-ubiquitin (P4D1, Santa Cruz, SC-8017), rat anti-LAMP-1 (Developmental Studies Hybridoma Bank, 1D4B), rabbit antirab5 (Cell Signaling, 2143), rabbit anti-rab7 (Cell Signaling Technologies, 9367), rabbit anti-p-mTOR (S2448; Cell Signaling Technology, 2971), rabbit anti-mTOR (Cell Signaling Technology, 2972), rabbit anti-p-p70S6K (T389; Cell Signaling Technology, 9234), rabbit anti-p70S6K (Cell Signaling Technology, 2708), mouse anti-fodrin antibody (ENZO Life Sciences, BML-FG6090), rabbit anti-calbindin-D28K (Swant, 300), mouse anti-GAPDH (EMD Millipore, mab374), and rabbit anti-actin antibody (Sigma-Aldrich, A2066). After extensive washes with TBST, blots were incubated with the appropriate horseradish peroxidase (HRP)-conjugated secondary antibodies for $1 \mathrm{~h}$ at room temperature. The secondary antibodies used included HRP-conjugated anti-rabbit (Santa Cruz, sc-2004), HRP-conjugated anti-mouse (Santa Cruz, sc2005), HRP-conjugated anti-guinea pig (Sigma-Aldrich, A5545), and HRP-conjugated anti-rat antibody (Santa Cruz, sc-2006). Specific bands were visualized using an enhanced chemiluminescence kit (ECL; PerkinElmer Waltham, NEL105). The relative intensity of each band was measured using ImageJ Imaging Software (National Institute of Health, Bethesda, MD). For immunofluorescence staining, cells were grown on coverslips, and treated, fixed with $4 \%$ paraformaldehyde (EMS, 15170) at room temperature for $15 \mathrm{~min}$, and permeabilized with $0.1 \%$ saponin (Sigma, S4521) for 10 min. Coverslips were washed and incubated in PBS containing $0.2 \%$ Triton X100 and 5\% normal goat serum (Invitrogen, 16210) for $1 \mathrm{~h}$ to block nonspecific sites. Subsequently, cells were incubated overnight at $4{ }^{\circ} \mathrm{C}$ with primary antibody in PBS containing $0.2 \%$ Triton $\mathrm{X}-100$ and $1 \%$ normal goat serum. After washing with PBS, cells were incubated at room temperature for $1 \mathrm{~h}$ with the appropriate secondary antibody. These included Alexa488-conjugated goat antiguinea pig IgG (Invitrogen, A11073), Alexa 488conjugated goat anti-rabbit IgG (Invitrogen, A11008), Alexa 568-conjugated goat anti-rabbit IgG (Invitrogen, 
A11011), and Alexa 568-conjugated goat anti-mouse IgG (Invitrogen, A11004). For counterstaining nuclei, $1 \mu \mathrm{g} / \mathrm{ml}$ Hoechst 33258 (Molecular Probes, H-1398) was used. Cells were then mounted with Vectashield (Vector Laboratories, H1000). Fluorescent images were acquired using a confocal laser scanning microscope (Zeiss LSM 700). As previously described ${ }^{25,26}$, acquired images were analyzed for LC3 puncta using ImageJ Imaging Software.

\section{Analyses of lysosomal acidification and mitochondrial membrane potential}

Following drug treatment, cells were incubated with $0.5 \mu \mathrm{M}$ LysoTracker Red DND-99 (Life Technologies, L7528) or $0.75 \mu \mathrm{M}$ MitoTracker Red CMXRos (Life Technologies, M7512) for $30 \mathrm{~min}$ at $37^{\circ} \mathrm{C}$. Subsequently, cells were washed twice with PBS. Fluorescent images of live cells were observed under an Axio Observer A1 microscope (Carl Zeiss). Cathepsin B activity was examined using the Magic Red Cathepsin B detection kit (ImmunoChemistry Technologies, 937). Briefly, Magic Red Cathepsin B reagent was added to the cell medium, and after $1 \mathrm{~h}$, cells were washed twice with PBS. Fluorescent images were taken using an Axio Observer A1 microscope. For monitoring autophagic flux, MN9D cells plated on poly-D-lysine-coated culture dishes were cultivated for 2 days and subjected to transient transfection with an mRFP-EGFP tandem fluorescent-tagged LC3 probe (a generous gift from Prof. Tamotsu Yoshimori at Osaka University, Japan) for $24 \mathrm{~h}$ using Lipofectamine 2000 (Thermo Fisher Scientific, 11668019) as recommended by the supplier. Drug treatment was performed $24 \mathrm{~h}$ post-transfection.

\section{Statistics}

Data were expressed as means \pm standard error of the mean (SEM). from at least three independent experiments. The differences were determined by one-way ANOVA or two-tailed unpaired $t$-test using GraphPad Prism 5. Values of ${ }^{* * * * * *} p<0.0001,{ }^{* * * * *} p<0.001, " p<0.005$, or $" p<0.05$ were considered statistically significant.

\section{Acknowledgements}

This work was supported by the Brain Research Program through the National Research Foundation of Korea (NRF) funded by the Korean Government (2017M37A1025369 to Y.J.O.), and partly by NRF-2016R1A5A1010764 (to J.W.C.).

\section{Author details}

'Department of Systems Biology, Yonsei University College of Life Science and Biotechnology, Seoul 03722, Korea. ${ }^{2}$ Glycosylation Network Research Center, Yonsei University, Seoul 03722, Korea. ${ }^{3}$ Neuropharmacology and Toxicology Program, College of Pharmacy, Kangwon National University, Chunchon 24341, Korea

\section{Conflict of interest}

The authors declare that they have no conflict of interest.

\section{Publisher's note}

Springer Nature remains neutral with regard to jurisdictional claims in published maps and institutional affiliations.

The online version of this article (https://doi.org/10.1038/s41420-019-0210-6) contains supplementary material, which is available to authorized users.

Received: 3 July 2019 Revised: 30 July 2019 Accepted: 2 August 2019 Published online: 19 August 2019

References

1. Jankovic, J. Parkinson's disease: clinical features and diagnosis. J. Neurol., Neurosurg., Psychiatry 79, 368-376 (2008).

2. Dauer, W. \& Przedborski, S. Parkinson's disease: mechanisms and models. Neuron 39, 889-909 (2003).

3. Thomas, B. \& Beal, M. F. Parkinson's disease. Hum. Mol. Genet. 2, R183-R194 (2007). 16 Spec No.

4. Olanow, C. W. The pathogenesis of cell death in Parkinson's disease-2007. Mov. Disord.: Off. J. Mov. Disord. Soc. 22(Suppl 17), S335-S342 (2007).

5. Corti, O., Lesage, S. \& Brice, A. What genetics tells us about the causes and mechanisms of Parkinson's disease. Physiol. Rev. 91, 1161-1218 (2011).

6. Michel, P. P., Hirsch, E. C. \& Hunot, S. Understanding dopaminergic cell death pathways in Parkinson disease. Neuron 90, 675-691 (2016).

7. Ghavami, S. et al. Autophagy and apoptosis dysfunction in neurodegenerative disorders. Prog. Neurobiol. 112, 24-49 (2014).

8. Erekat, N. S. Apoptosis and its Role in Parkinson's Disease, in Parkinson's Disease: Pathogenesis and Clinical Aspects. (eds. T. B. Stoker \& J. C. Greenland) (Codon Publications Copyright: The Authors., Brisbane, 2018).

9. Yuan, J., Amin, P. \& Ofengeim, D. Necroptosis and RIPK1-mediated neuroinflammation in CNS diseases. Nat. Rev. Neurosci. 20, 19-33 (2019).

10. Venderova, K. \& Park, D. S. Programmed cell death in Parkinson's disease. Cold Spring Harb. Perspect. Med. 2, a009365 (2012).

11. Karabiyik, C., Lee, M. J. \& Rubinsztein, D. C. Autophagy impairment in Parkinson's disease. Essays Biochem. 61, 711-720 (2017).

12. Moors, T. E. et al. Therapeutic potential of autophagy-enhancing agents in Parkinson's disease. Mol. Neurodegener. 12, 11 (2017).

13. Xilouri, M., Brekk, O. R. \& Stefanis, L. Autophagy and alpha-synuclein: relevance to Parkinson's disease and related synucleopathies. Mov. Disord.: Off. J. Mov. Disord. Soc. 31, 178-192 (2016).

14. Wong, E. \& Cuervo, A. M. Autophagy gone awry in neurodegenerative diseases. Nat. Neurosci. 13, 805-811 (2010).

15. Nixon, R. A. The role of autophagy in neurodegenerative disease. Nat. Med. 19 983-997 (2013).

16. Sanchez-Perez, A. M., Claramonte-Clausell, B., Sanchez-Andres, J. V. \& Herrero, M. T. Parkinson's disease and autophagy. Park.'s. Dis. 2012, 429524 (2012).

17. Hara, T. et al. Suppression of basal autophagy in neural cells causes neurodegenerative disease in mice. Nature 441, 885-889 (2006).

18. Komatsu, M. et al. Loss of autophagy in the central nervous system causes neurodegeneration in mice. Nature 441, 880-884 (2006).

19. Yang, Z. \& Klionsky, D. J. Eaten alive: a history of macroautophagy. Nat. Cell Biol. 12, 814-822 (2010)

20. Pickrell, A. M. \& Youle, R. J. The roles of PINK1, parkin, and mitochondrial fidelity in Parkinson's disease. Neuron 85, 257-273 (2015).

21. Cuervo, A. M., Stefanis, L., Fredenburg, R., Lansbury, P. T. \& Sulzer, D. Impaired degradation of mutant alpha-synuclein by chaperone-mediated autophagy. Sci. (New Y., N. Y.) 305, 1292-1295 (2004).

22. Han, B. S. et al. Caspase-dependent and -independent cell death pathways in primary cultures of mesencephalic dopaminergic neurons after neurotoxin treatment. J. Neurosci.: Off. J. Soc. Neurosci. 23, 5069-5078 (2003).

23. Choi, W. S. et al. Phosphorylation of p38 MAPK induced by oxidative stress is linked to activation of both caspase-8- and -9-mediated apoptotic pathways in dopaminergic neurons. J. Biol. Chem. 279, 20451-20460 (2004).

24. Choi, W. S. et al. Two distinct mechanisms are involved in 6-hydroxydopamine- and MPP + -induced dopaminergic neuronal cell death: role of caspases, ROS, and JNK. J. Neurosci. Res. 57, 86-94 (1999).

25. Lim, J. et al. Binding preference of p62 towards LC3-II during dopaminergic neurotoxin-induced impairment of autophagic flux. Autophagy 7, 51-60 (2011). 
26. Lim, J. et al. Nigericin-induced impairment of autophagic flux in neuronal cells is inhibited by overexpression of Bak. J. Biol. Chem. 287, 23271-23282 (2012).

27. Chung, Y. et al. Dysregulated autophagy contributes to caspase-dependent neuronal apoptosis. Cell Death Dis. 9, 1189 (2018).

28. Choi, H. K., Won, L., Roback, J. D., Wainer, B. H. \& Heller, A. Specific modulation of dopamine expression in neuronal hybrid cells by primary cells from different brain regions. Proc. Natl Acad. Sci. USA 89, 8943-8947 (1992).

29. Choi, H. K. et al. Immortalization of embryonic mesencephalic dopaminergic neurons by somatic cell fusion. Brain Res. 552, 67-76 (1991).

30. Yuan, H. H., Chen, R. J., Zhu, Y. H., Peng, C. L. \& Zhu, X. R. The neuroprotective effect of overexpression of calbindin-D(28k) in an animal model of Parkinson's disease. Mol. Neurobiol. 47, 117-122 (2013).

31. McMahon, A. et al. Calbindin-D28k buffers intracellular calcium and promotes resistance to degeneration in PC12 cells. Brain Res. Mol. Brain Res. 54, 56-63 (1998).

32. Choi, W. S., Lee, E., Lim, J. \& Oh, Y. J. Calbindin-D28K prevents drug-induced dopaminergic neuronal death by inhibiting caspase and calpain activity. Biochem. Biophys. Res. Commun. 371, 127-131 (2008)

33. Dehay, B. et al. Pathogenic lysosomal depletion in Parkinson's disease. J. Neurosci:: Off. J. Soc. Neurosci. 30, 12535-12544 (2010).

34. Lonskaya, I., Hebron, M. L., Algarzae, N. K., Desforges, N. \& Moussa, C. E. Decreased parkin solubility is associated with impairment of autophagy in the nigrostriatum of sporadic Parkinson's disease. Neuroscience 232, 90-105 (2013).

35. Anglade, P. et al. Apoptosis and autophagy in nigral neurons of patients with Parkinson's disease. Histol. Histopathol. 12, 25-31 (1997).

36. Katsuragi, Y., Ichimura, Y. \& Komatsu, M. p62/SQSTM1 functions as a signaling hub and an autophagy adaptor. FEBS J. 282, 4672-4678 (2015).

37. Nakamura, S. \& Yoshimori, T. New insights into autophagosome-lysosome fusion. J. Cell Sci. 130, 1209-1216 (2017).

38. Kimura, S., Noda, T. \& Yoshimori, T. Dissection of the autophagosome maturation process by a novel reporter protein, tandem fluorescent-tagged LC3. Autophagy 3, 452-460 (2007).

39. Hoyer-Hansen, M. et al. Control of macroautophagy by calcium, calmodulindependent kinase kinase-beta, and Bcl-2. Mol. Cell 25, 193-205 (2007).

40. Mattson, M. P. Calcium and neurodegeneration. Aging Cell 6, 337-350 (2007)

41. Bezprozvanny, I. Calcium signaling and neurodegenerative diseases. Trends Mol. Med. 15, 89-100 (2009).

42. Fairless, R., Williams, S. K. \& Diem, R. Dysfunction of neuronal calcium signalling in neuroinflammation and neurodegeneration. Cell Tissue Res. 357, 455-462 (2014).

43. Pchitskaya, E., Popugaeva, E. \& Bezprozvanny, I. Calcium signaling and molecular mechanisms underlying neurodegenerative diseases. Cell Calcium 70, 87-94 (2018).

44. Schapira, A. H., Olanow, C. W., Greenamyre, J. T. \& Bezard, E. Slowing of neurodegeneration in Parkinson's disease and Huntington's disease: future therapeutic perspectives. Lancet (Lond., Engl.) 384, 545-555 (2014).

45. Swart, T. \& Hurley, M. J. Calcium channel antagonists as disease-modifying therapy for Parkinson's disease: therapeutic rationale and current status. CNS Drugs 30, 1127-1135 (2016).

46. Surmeier, D. J., Halliday, G. M. \& Simuni, T. Calcium, mitochondrial dysfunction and slowing the progression of Parkinson's disease. Exp. Neurol. 298, 202-209 (2017).

47. Cali, T., Ottolini, D. \& Brini, M. Calcium signaling in Parkinson's disease. Cell Tissue Res. 357, 439-454 (2014).
48. Yamada, T., McGeer, P. L., Baimbridge, K. G. \& McGeer, E. G. Relative sparing in Parkinson's disease of substantia nigra dopamine neurons containing calbindin-D28K. Brain Res. 526, 303-307 (1990).

49. Damier, P., Hirsch, E. C., Agid, Y. \& Graybiel, A. M. The substantia nigra of the human brain. II. Patterns of loss of dopamine-containing neurons in Parkinson's disease. Brain: A J. Neurol. 122(Pt 8), 1437-1448 (1999).

50. Lavoie, B. \& Parent, A. Dopaminergic neurons expressing calbindin in normal and parkinsonian monkeys. Neuroreport 2, 601-604 (1991).

51. lacopino, A., Christakos, S., German, D., Sonsalla, P. K. \& Altar, C. A. CalbindinD28K-containing neurons in animal models of neurodegeneration: possible protection from excitotoxicity. Brain Res. Mol. Brain Res. 13, 251-261 (1992).

52. German, D. C., Manaye, K. F., Sonsalla, P. K. \& Brooks, B. A. Midbrain dopaminergic cell loss in Parkinson's disease and MPTP-induced parkinsonism: sparing of calbindin-D28k-containing cells. Ann. New Y. Acad. Sci. 648, 42-62 (1992).

53. Furukawa, K. et al. Plasma membrane ion permeability induced by mutant alpha-synuclein contributes to the degeneration of neural cells. J. Neurochem. 97, 1071-1077 (2006)

54. Follett, J., Darlow, B., Wong, M. B., Goodwin, J. \& Pountney, D. L. Potassium depolarization and raised calcium induces alpha-synuclein aggregates. Neurotox. Res. 23, 378-392 (2013).

55. Choi, W. S. et al. Cleavage of Bax is mediated by caspase-dependent or -independent calpain activation in dopaminergic neuronal cells: protective role of Bcl-2. J. Neurochem. 77, 1531-1541 (2001).

56. Oh, Y. J., Wong, S. C., Moffat, M. \& O'Malley, K. L. Overexpression of BCl-2 attenuates MPP + , but not 6-ODHA, induced cell death in a dopaminergic neuronal cell line. Neurobiol. Dis. 2, 157-167 (1995).

57. Hwang, J. Y. et al. Proteolytic degradation and potential role of onconeural protein cdr2 in neurodegeneration. Cell Death Dis. 7, e2240 (2016).

58. Kim, C. et al. Gel-based protease proteomics for identifying the novel calpain substrates in dopaminergic neuronal cell. J. Biol. Chem. 288, 36717-36732 (2013).

59. Han, B. S., Noh, J. S., Gwag, B. J. \& Oh, Y. J. A distinct death mechanism is induced by 1-methyl-4-phenylpyridinium or by 6-hydroxydopamine in cultured rat cortical neurons: degradation and dephosphorylation of tau. Neurosci. Lett. 341, 99-102 (2003).

60. Decuypere, J. P., Bultynck, G. \& Parys, J. B. A dual role for $\mathrm{Ca}(2+)$ in autophagy regulation. Cell Calcium 50, 242-250 (2011).

61. Criollo, A. et al. Regulation of autophagy by the inositol trisphosphate receptor. Cell Death Differ. 14, 1029-1039 (2007).

62. Khan, M. T. \& Joseph, S. K. Role of inositol trisphosphate receptors in autophagy in DT40 cells. J. Biol. Chem. 285, 16912-16920 (2010).

63. Medina, D. L. et al. Lysosomal calcium signalling regulates autophagy through calcineurin and TFEB. Nat. Cell Biol. 17, 288-299 (2015).

64. Pena-Llopis, S. et al. Regulation of TFEB and V-ATPases by mTORC1. EMBO J. 30, 3242-3258 (2011).

65. Surmeier, D. J. Calcium, ageing, and neuronal vulnerability in Parkinson's disease. Lancet Neurol. 6, 933-938 (2007).

66. Kim, C., Lee, J., Ko, Y. U. \& Oh, Y. J. Cyclin-dependent kinase 5-mediated phosphorylation of CHIP promotes the tAIF-dependent death pathway in rotenone-treated cortical neurons. Neurosci. Lett. 662, 295-301 (2018).

67. Galluzzi, L. et al. Guidelines for the use and interpretation of assays for monitoring cell death in higher eukaryotes. Cell Death Differ. 16, 1093-1107 (2009). 